\title{
Attribution of recent trends in temperature extremes over China: role of changes in anthropogenic aerosol emissions over Asia
}

Article

Accepted Version

Chen, W., Dong, B., Wilcox, L., Luo, F., Dunstone, N. and Highwood, E. J. (2019) Attribution of recent trends in temperature extremes over China: role of changes in anthropogenic aerosol emissions over Asia. Journal Of Climate, 32. pp. 7539-7560. ISSN 1520-0442 doi: https://doi.org/10.1175/JCLI-D-18-0777.1 Available at https://centaur.reading.ac.uk/85992/

It is advisable to refer to the publisher's version if you intend to cite from the work. See Guidance on citing.

To link to this article DOI: http://dx.doi.org/10.1175/JCLI-D-18-0777.1

Publisher: American Meteorological Society

All outputs in CentAUR are protected by Intellectual Property Rights law, including copyright law. Copyright and IPR is retained by the creators or other copyright holders. Terms and conditions for use of this material are defined in the End User Agreement. 


\section{www.reading.ac.uk/centaur}

\section{CentAUR}

Central Archive at the University of Reading

Reading's research outputs online 


\section{Attribution of recent trends in temperature extremes over China: role of changes}

\section{in anthropogenic aerosol emissions over Asia}

Wei Chen ${ }^{1, *}$, Buwen Dong ${ }^{2}$, Laura Wilcox ${ }^{2}$, Feifei Luo ${ }^{3}$, Nick Dunstone ${ }^{4}$, and Eleanor J. Highwood ${ }^{5}$

\footnotetext{
1. State Key Laboratory of Numerical Modeling for Atmospheric Sciences and Geophysical Fluid Dynamics, Institute of Atmospheric Physics, Chinese Academy of Sciences, Beijing, China

2. National Centre for Atmospheric Science-Climate, Department of Meteorology, University of Reading, Reading, UK

3. Nansen-Zhu International Research Centre and Climate Change Research Center, Institute of Atmospheric Physics, Chinese Academy of Sciences, Beijing, China

4. Met Office Hadley Centre, Exeter, UK

${ }^{5}$ Department of Meteorology, University of Reading, Reading, UK
}

*Corresponding author:

Wei Chen,

Institute of Atmospheric Physics,

Chinese Academy of Sciences,

P. O. Box 9804, Beijing 100029, China,

Tel: +86-10-8299-5249

Fax: +86-10-8299-5172

E-mail: chenwei@mail.iap.ac.cn typeset copyedited article will replace the EOR at the above DOI when it is published. 
Observations indicate large changes in temperature extremes over China during

3 the last four decades, exhibiting as significant increases in the amplitude and

4 frequency of hot extremes and decreases in the amplitude and frequency of cold

5 extremes. An ensemble of transient experiments with a fully coupled

6 atmosphere-ocean model HadGEM3-GC2, including both anthropogenic forcing and

7 natural forcing, successfully reproduces the spatial pattern and magnitude of observed

8 historical trends in both hot and cold extremes. The model simulated trends in

9 temperature extremes primarily come from the positive trends in clear sky longwave radiation, which is mainly due to the increases in greenhouse gases (GHGs). An ensemble of sensitivity experiments with Asian anthropogenic aerosol (AA) emissions fixed at their 1970s levels tends to overestimate the trends in temperature extremes, indicating that local AA emission changes have moderated the trends in these temperature extremes over China. The recent increases in Asian AA drive cooling trends over China by inducing negative clear sky shortwave radiation directly through the aerosol-radiation interaction, which partly offsets the strong warming effect by GHG changes. The cooling trends induced by Asian AA changes are weaker over Northern China during summer, which is due to the warming effect by positive shortwave cloud radiative effect through the AA-induced atmosphere-cloud feedback. This accounts for the observed north-south gradients of the historical trends in some 21 temperature extremes over China, highlighting the importance of local Asian AA 
emission changes on spatial heterogeneity of trends in temperature extremes.

Key words: trends in temperature extremes; China; transient experiments; historical forcing changes; increases in Asian anthropogenic aerosol emissions

\section{Introduction}

The global and regional climate has changed dramatically during the past decades. The Fifth Assessment Report (AR5) of Intergovernmental Panel on Climate Change (IPCC) reported a warming trend in global mean surface air temperature (SAT) during the historical period from (IPCC, 2013). Consistent with global warming, robust changes in temperature extremes have been observed in many regions around the world, with more hot extremes and fewer cold extremes (e.g., Alexander et al. 2006; Donat et al. 2013). Given the serious impacts of temperature extremes on human activities, ecosystems, economic development and social stability (e.g., Meehl et al. 2000; Dìaz et al. 2005; Ainsworth and Ort 2010; Hertel and Rosch 2010), understanding the changes in temperature extremes and the underling drivers is of particular concern for both the scientific community and policy makers as they deal with climate changes and their impacts.

Widespread changes in temperature extremes, with increased hot extremes and decreased cold extremes, associated with the surface warming trends, have been observed in China (e.g., Qi and Wang 2012; Yu and Li 2015; Guan et al. 2015; Zhou et al. 2016; Dong et al. 2016a; Wang et al. 2017; Shi et al. 2018), and have been 
attributed to the combined effect of natural and anthropogenic forcing (e.g., Kosaka and Xie 2013; Trenberth et al. 2014; Steinman et al. 2015).

The North Atlantic and Pacific oceans are the key drivers of natural changes in temperature on multi-decadal timescales. The positive phase of the Atlantic multi-decadal Oscillation (AMO) contributed to the surface warming and increase of hot extremes and decrease of cold extremes over China since the mid-1990s (e.g., Hong et al. 2017; Shi et al. 2018). The central Pacific SST warming due to more frequent El Niño Modoki events might promote the warming trend after 1990, particularly over Northern China (Qi and Wang 2012). However, the natural variability alone cannot fully explain the sustained surface warming and trends in temperature extremes, since these natural causes have periodic oscillations.

Previous studies suggest that anthropogenic activities, represented as the total effect of greenhouse gas (GHG) concentrations and anthropogenic aerosol (AA) emissions, induce warming over China (e.g., Wen et al. 2013; Dong et al. 2016a; Yin et al. 2016). As a result, the anthropogenic impacts lead to increased hot extremes in Eastern China (Sun et al. 2014) and Northeast China (Dong et al. 2016a). Moreover, the anthropogenic changes contribute to some extremes events, such as the 2014 extreme hot and dry summer in Northeast China (Wilcox et al. 2015) and the 2013 mid-summer heat wave in Central-Eastern China (Ma et al. 2017).

The increase in GHG concentrations has a warming effect. The increased GHGs warm the surface by trapping more outgoing longwave radiation (e.g., Cubasch et al. 
2001; Dong et al. 2009, 2016b). Analysis of CMIP5 models indicated that the changes in GHGs play a dominant role in the warming trend over China (e.g., Song et al. 2014; Zhao et al. 2016). Coupled model time-slice experiments also suggested that the recent decadal changes in GHG forcing are the major factor for the decadal surface warming, increases of hot extremes and decreases of cold extremes over China across the mid-1990s (Chen and Dong 2018; Tian et al 2018). Thus, it is well accepted that increased GHG concentrations result in a warming trend over China.

However, there is no consensus about the effect of AA emissions on temperature extremes over China. On the one hand, the increased AA cools the surface via direct aerosol-radiation interaction (e.g., Hansen et al. 1997; Stevens and Feingold 2009). Such cooling trends over China induced by AA forcing changes have been identified by previous studies (e.g., Song et al. 2014; Zhao et al. 2016). On the other hand, a warming effect by AA changes over some regions of China has also been noted (Wen et al. 2013; Li et al. 2015; Tian et al. 2018). Chen and Dong (2018) further explained that the recent surface warming and increase in hot extremes over Northern China are contributed to by the changes in AA emissions through land surface and atmospheric feedback. However, the changes in AA emissions are not homogeneous globally. They have decreased over Europe and North America and increased over Asia since the 1970s (Dong et al. 2016a, b; Chen and Dong 2018), suggesting that the remote AA changes and the Asian AA changes may have different impacts. Previous studies have investigated the responses of temperature extremes over China to the changes in AA 
globally (e.g., Wen et al. 2013; Li et al. 2016; Zhao et al. 2016; Chen and Dong 2018; Tian et al. 2018). Nevertheless, it is not clear what the impacts of local Asian AA changes are in recent decades, especially their impacts on temperature extremes over China. Addressing this question is the main focus in this study.

A number of modeling approaches have been used in attribution studies. Some rely on an atmospheric general circulation model (AGCM) forced by prescribed sea surface temperatures (SSTs), with and without anthropogenic influences (e.g., Christidis et al. 2013; Kamae et al. 2014; Kim et al. 2015; Schaller et al. 2016). A potential limitation of AGCM experiments is the lack of explicit air-sea interaction, which causes an inconsistency in surface energy fluxes and can limit a model's ability to accurately simulate natural climate variability (e.g., Barsugli and Battisti 1998; He and Soden 2016). Moreover, a lack of air-sea coupling is a major source of bias in the circulation over monsoon region (Hendon et al. 2012; Zhu and Shukla 2013), and therefore may lead to erroneous attribution conclusions for circulation changes in East Asian summer monsoon (EASM), particularly for the response of circulation to the aerosol changes (Dong et al. 2017). To overcome these limitations, a fully coupled atmosphere-ocean general circulation model (CGCM) that allows for a dynamical ocean response and natural internal variability is used in this study.

Some previous studies have analyzed the impacts of anthropogenic forcing on the decadal changes of EASM and temperature extremes over China by performing time-slice experiments (Kim et al. 2016; Chen and Dong 2018; Tian et al. 2018). 
Time-slice simulations provide high signal to noise ratios to identify the mechanisms by which anthropogenic forcings have affected regional climate change. However, this kind of simulation fails to account for the transient nature of climate changes (e.g., Douville 2005; Goderniaux et al. 2011). For comparison with observed climate changes, especially about warming trends or trends in climate extremes, transient experiments are preferred. Therefore, a set of transient simulations based on a fully coupled system, emphasizing the slow adjustment responses to external forcing changes, is performed to understand the changes in temperature extremes over China. In this study we will quantify the contribution of historical forcing to observed trends in temperature extremes over China and determine whether the recent increases in Asian AA emissions play an important role in the recent changes. We will also identify the physical processes involved in the historical trends. In Section 2 we describe the observational dataset and model experimental design. The changes in temperature extremes over China in observations and in a set of transient simulations with all natural and anthropogenic forcings are illustrated in Section 3. In Section 4 we quantify the role of recent Asian AA changes in the trends of temperature extremes. In Section 5 we demonstrate the physical processes involved in the model simulated responses of trends in temperature extremes to the historical forcing changes and to the Asian AA changes. Conclusions are summarized in Section 5.

\section{Observational datasets and model experiments design}

The observations used in this study are the homogenized datasets of daily 
maximum temperature (Tmax) and minimum temperature (Tmin) series from 753 stations in China from 1971 to 2013 (Li et al. 2016). Considering the various climatic types in China, we divide the 753 stations into three sub-regions: northern China (NC) with 331 stations north of $35^{\circ} \mathrm{N}$, southeastern China (SEC) with 334 stations south of $35^{\circ} \mathrm{N}$ and east of $105^{\circ} \mathrm{E}$, and southwestern China (SWC) with 88 stations south of $35^{\circ} \mathrm{N}$ and west of $105^{\circ} \mathrm{E}$, following Chen and Dong (2018; the distribution of these stations are shown in their Fig. 2a). The hot extreme indices are: annual hottest day temperature (TXx), warmest night temperature (TNx), summer days (SU), and tropical nights (TR). SU are defined as the annual number of days when Tmax $>25^{\circ} \mathrm{C}$. TR is the annual number of days when Tmin $>20^{\circ} \mathrm{C}$. The cold extremes indices are: annual coldest day temperature (TXn), coldest night temperature (TNn), ice days (ID), and frost days (FD). ID are defined as the annual number of days when $\operatorname{Tmax}<0^{\circ} \mathrm{C}$. FD is the annual number of days when $\operatorname{Tmin}<0^{\circ} \mathrm{C}$.

The model used is the Met Office Unified Model-Global Coupled configuration 2 (HadGEM3-GC2). This version of the model includes the ENDGAME (Even Newer Dynamics for Global Atmospheric Modelling of the Environment) dynamical core (Wood et al. 2014) and the CLASSIC aerosol scheme (Bellouin et al. 2007). It is described in detail by Williams et al. (2015). The model was run with a vertical resolution of 85 levels in the atmosphere and 75 levels in the ocean. A horizontal resolution of $\mathrm{N} 216$ ( $\sim 60 \mathrm{~km}$ in the mid-latitudes) was used for the atmosphere and $0.25^{\circ}$ for the ocean. The historical transient experiments are performed to compare 
with observed climate change. The model integration period for the historical simulation is from November 1959 to 2014. The model ocean and sea ice are initialized from four historical transient runs that started in 1860 , so we do not anticipate any spin-up issues. The All forcing transient experiment, 'All', includes historical forcings (anthropogenic and natural) following CMIP5 historical forcings from 1971 to 2005 and then RCP4.5 to 2013. To illustrate the impacts of Asian AA changes, we performed a 'Fixasia' sensitivity experiment with AA emissions over Asia fixed at their 1971 to 1980 mean, but with AA emissions outside Asia and other forcings the same as those in the All forcing experiments. The difference between the All forcing and the Fixasia experiments (All minus Fixasia) represents the impact of increases in AA over Asia from the 1970s to 2013. The changes in aerosol emissions during this period exhibit a large positive trend over South Asia and East Asia (Fig. 1). In this study, we will identify the role of these increases in Asian AA for the changes in temperature extremes over China. The ensemble mean of four members for each experiment is analyzed.

Figure 2 shows the comparison in climatological mean aerosol optical depth and surface air temperature from 1980 to 2013 between model simulations and observations. The climatological mean AOD shows large value over most parts of China during summer, and is particularly large over over Eastern China (Fig. 2a). Region with large AOD shifts southward to the southeastern China by the mean flow during winter (Fig. 2b). HadGEM3-GC2 is able to reproduce the observed AOD 
distribution over China. However, the modeled AOD is slightly overestimated over southern China and underestimated over northern China during summer (Fig. 2c), and tends to be underestimated over China during winter (Fig. 2d).

The modeled seasonal mean temperature indicates a warm bias over northwestern China and a cold bias over SWC during summer (with a magnitude of $0.5^{\circ} \mathrm{C}$; Fig. 2e) and a cold bias over most region of China during winter, particularly over SWC, with a cold bias more than $2{ }^{\circ} \mathrm{C}$ (Fig. 2f). Such a cold bias is typical of the current generation of climate models (e.g. Bannister et al. 2017).

\section{Trends in temperature extremes over China during the last four decades}

Figure 3 illustrates the times series and spatial patterns in linear trends of hot temperature extreme anomalies over China in observations and in the All forcing transient simulations. In observations, these time series clearly show robust positive trends in TXx, TNx, SU and TR since the 1970s (Fig. 3), in addition to the interannual variability. These trends are very well reproduced by the model simulations (Fig. 3). The good agreement between the model simulated trends of hot extremes with those in observations indicates a predominant role of historical forcing in the trends in hot extremes over China during the last four decades.

Positive trends in hot extremes are exhibited in most regions of China in observations, although there are some spatial variations (Fig. 3e-h). These spatial patterns in trends of hot extremes are realistically simulated in the HadGEM3-GC2 All forcing experiment (Fig. 3i-1). For TXx, the positive trends in observations are 
shown over most regions of China with some significant spatial variations with a magnitude about $0.4{ }^{\circ} \mathrm{C} / 10 \mathrm{yr}$ over SWC and some small regions over NC (Fig. 3e). These positive trends are also seen in the All forcing transient simulations although model simulated trends show smaller regional variations (Fig. 3i). The magnitude of the model simulated trends ranges from $0.2{ }^{\circ} \mathrm{C} / 10 \mathrm{yr}$ to $0.4{ }^{\circ} \mathrm{C} / 10 \mathrm{yr}$, with a large magnitude over NC.

An increase in the magnitude of TNx is seen over China in observations (Fig. 3f). The linear trends in TNx exhibit a north-south gradient, with a magnitude of 0.37 ${ }^{\circ} \mathrm{C} / 10 \mathrm{yr}$ in northern China (north of $35^{\circ} \mathrm{N}$ ), in comparison to $0.27^{\circ} \mathrm{C} / 10 \mathrm{yr}$ in southern China (south of $35^{\circ} \mathrm{N}$ ). In the All forcing transient experiments, both the positive trend of TNx and the north-south gradient in this trend are well captured by the model (Fig. 3j) with a value of $0.34{ }^{\circ} \mathrm{C} / 10 \mathrm{yr}$ averaged over northern China and $0.23{ }^{\circ} \mathrm{C} / 10 \mathrm{yr}$ over southern China. For SU and TR, the observed positive trends cover a large part of China, except over the Tibetan Plateau (Fig. 3g and h). In response to All forcing changes, the spatial patterns in linear trends of SU and TR are comparable to those in observations, with pattern correlations of 0.67 for SU and 0.76 for TR, although the magnitude of the modeled trends is a slightly smaller (Fig. 3k and 1). In summary, the All forcing simulations successfully reproduce the spatial patterns of positive trends in hot extremes over China. In particular, the observed north-south gradients of the trends in TXx and TNx are well captured.

Time series of cold extremes are shown in Fig. 4. In observations, there are 
positive trends in TXn and TNn and negative trends in ID and FD (Fig. 4). These

211 changes in cold extremes are well reproduced by the transient simulations with All

212 forcing changes. The good match of the linear trends in cold extreme indices between

213 the All forcing transient simulations and observations indicates a dominant role of

214 historical forcing in the observed trends of cold extremes over China during the last

215 four decades.

216 For spatial patterns, the positive trends in TXn and TNn and negative trends in ID

217 and FD are shown over most regions of China in observations (Fig. 4e-h). These

218 patterns are well simulated by HadGEM3-GC2 with All forcing changes (Fig. 4i-1),

219 although the positive trends over SWC are slightly overestimated by the model, which

220 are likely due to the cold bias over this region (Fig. 2f). The observed positive trends

221 in TXn and TNn display a regional variation with large positive trends over southern

222 China, with a magnitude more than $0.4{ }^{\circ} \mathrm{C} / 10 \mathrm{yr}$ (Fig. $4 \mathrm{e}$ and $\mathrm{f}$ ). The transient

223 simulations with All forcing changes not only capture the regional mean positive

224 trends in TXn and TNn, but also reproduce some of the regional variations in these

225 trends (Fig. 4i and j). The spatial patterns of negative trends in ID and FD in response

226 to All forcing are similar to those in observations, with pattern correlations of 0.53 for

227 ID and 0.61 for FD. In summary, the spatial patterns of linear trends in cold extremes

228 can be reasonably simulated by transient simulations with All forcing changes.

229 The results above are based on the ensemble mean of four members for each

230 experiment. In response to All forcing, all four ensemble members reproduce the 
positive trends in hot extremes and cold temperature extremes and negative trends in cold day extremes. The spread of these linear trends in temperature extremes among the four ensemble members is small relative to the magnitude of the ensemble mean trends (about $10 \%$ of the ensemble mean trends). Thus, all the four ensemble members realistically reproduce the observed linear trends of temperature extremes, demonstrating that the ensemble mean trend is robust response to external forcing.

HadGEM3-GC2 is generally able to realistically reproduce the spatial pattern of observed trends in temperature extremes over China. However, the model tends to overestimate the positive trends in hot extremes over northwestern China and underestimate the negative trends in ID and FD over SWC (not shown). The model deficiency in reproducing trends in threshold-based metrics of temperature extremes, such as ID and FD, is likely to arise from the model bias in seasonal mean temperature (Fig. 2e and f), even though it correctly captures the observed temperature trend.

The magnitudes of the China-mean trends in both hot and cold extremes are summarized in Fig. 5. Quantitatively, the model simulated changes in response to All forcing changes reproduce the observed changes in temperature extremes over China realistically. In the All forcing experiment, the linear trend in TXx (TNx) averaged over China is $0.28^{\circ} \mathrm{C} / 10 \mathrm{yr}\left(0.29^{\circ} \mathrm{C} / 10 \mathrm{yr}\right)$, which is comparable to the observed trends of $0.24^{\circ} \mathrm{C} / 10 \mathrm{yr}\left(0.31{ }^{\circ} \mathrm{C} / 10 \mathrm{yr}\right)$. The linear trends of TXn and TNn averaged over China in response to All forcing changes are $0.23{ }^{\circ} \mathrm{C} / 10 \mathrm{yr}$ and $0.30{ }^{\circ} \mathrm{C} / 10 \mathrm{yr}$, which are 
similar to observed changes of $0.24{ }^{\circ} \mathrm{C} / 10 \mathrm{yr}$ and $0.38^{\circ} \mathrm{C} / 10 \mathrm{yr}$. The magnitudes of the trends in SU, TR, ID and FD in All forcing experiment also resemble to those in observations.

The good reproduction of observed trends in temperature extremes by HadGEM3-GC2 in the historical the All forcing experiment indicates a dominant role of historical forcing changes in observed trends in temperature extremes over China during the last four decades. In the next section we quantify the contribution of the recent increase of Asian AA emissions to these changes in temperature extremes over China.

\section{Role of recent Asian AA changes in the trends of temperature extremes.}

Figure 6 shows the spatial pattern of linear trends in hot extremes in the Fixasia experiments and All minus Fixasia experiments, which shows the effect of increasing Asian aerosol emissions. With fixed Asian AA emissions, the hot extremes exhibit more or less uniform positive trends over China (Fig. 6a-d). The difference between observations and the Fixasia experiment indicates an overestimation of observed trends in hot extremes over most regions of China(Fig. 6e-h), indicating that the positive trends in hot extremes over China cannot be accurately reproduced without Asian AA changes. The uniformly positive trends of hot extremes in the Fixasia experiments are likely to be mainly contributed to by the changes in GHGs globally, being long-lived and uniformly distributed (Penner et al. 2001; Wang 2004), which cause a more or less uniform warming over China (e.g., Zhao et al. 2016). 

as well as in SU and TR, are simulated over a large area of China, particularly over southern China (Fig. 6i-1), suggesting a cooling effect of Asian AA on the hot temperature extremes. This cooling effect driven by the Asian AA changes partly offsets the warming effect mainly induced by GHG changes. The cooling effect induced by Asian AA changes is weak over NC, with scattered positive trends over some regions of NC. This spatial heterogeneity of trends in response to Asian AA changes reshapes the more or less uniformly positive trends in the Fixasia simulations, and accounts for the north-south gradient in the trends of hot extremes in the All forcing transient simulations and observations.

For hot extremes, the differences between observations and the Fixasia experiment in the trends in TXx and TNx show positive changes over large parts of China, particularly over southern China (Fig. 6e and f). The differences in trends in SU and TR exhibit negative changes in northwestern China and positive changes in southern China and east of northeastern China (Fig. 6g and h). These differences are opposite to the patterns in the trends of hot extremes in response to Asian AA increase (Fig. 6i-1), suggesting that including Asian-AA change improves the agreement between the model simulation and observations in large domain in these extreme indices.

Linear trends in cold extremes in the transient experiments without Asian AA changes and those induced by Asian AA changes alone are illustrated in Fig. 7. The 
Fixasia simulations broadly reproduce the positive trends in TXn and TNn and the negative trends in ID and FD (Figs. 7a-d), which explain large parts of the model simulated changes in the trends of cold extremes in the All forcing transient simulations. Without Asian AA changes, however, the model simulated trends differ from observed trends somewhat (Fig. 7e-h), implying either a role of local Asian AA change in the trends in cold extremes or a model deficiency. In response to changes in Asian AA, the negative trends in TXn and TNn and the positive trends in ID and FD are exhibited over China, although opposite trends are shown in some scatter areas (Fig. 7i-1). Particularly, the cooling effect is significantly strong over SWC in response to Asian AA changes, exhibiting strong negative trends in TXn and TNn and positive trends in ID and FD, partly offset the warming trends in the Fixasia experiments. The heterogeneous distribution of trends in response to Asian AA changes contributes to the model simulated regional variations of cold extremes in response to All forcing changes.

The Fixasia simulations tend to have positive biases for the trends in TXn and TNn over northwestern China and SWC (Fig. 7e and f), negative biases for the trends in ID over SWC (Fig. 7g) and positive biases for the trends in FD over northern China (Fig. 7h). These biases are opposite to the changes in these extreme indices in response to Asian AA increase (Fig. 7i-1). Thus, including Asian AA changes also improve the model simulated trends in cold extremes compared with observations.

Figure 8 shows the temperature extreme indices averaged over China as a whole 
and over the three sub-regions in observations and in response to different forcings. For the whole region of China (Fig. 8a and b), the model simulated changes in response to All forcing changes quantitatively reproduce the observed changes in temperature extremes over China, as shown in Fig. 5. The positive trends in hot extremes (TXx, TNx, SU and TR), the positive trends in cold temperatures (TXn and TNn) and negative trends in cold days (ID and FD) are captured in the Fixasia simulations. The magnitudes of these trends in some temperature extremes in the Fixasia experiments are stronger than those in response to All forcing changes, indicating that the model tends to overestimate the trends in some of these temperature extremes without the influence of Asian AA increases. Note that there is basically no significant difference in trends in extremes day indices between the regional average trends from the All and the Fixasia experiment. This is likely due to the model's bias in seasonal mean temperature (Fig. 2e and f), which makes threshold crossing metrics, such as $\mathrm{SU}, \mathrm{TR}, \mathrm{ID}$ and FD, tend to be less reliable in the mode. Such biases may also suppresses the difference between the All and the Fixasia experiments, if the response to AA is not sufficient to cause a temperature response that crosses the pre-defined threshold, in the event that the threshold is far from the model's base state.

The increases in Asian AA emissions drive a cooling effect with negative trends in TXx, TNx, SU, TR, TXn and TNn and positive trends in ID and FD. The cooling effect of Asian AA increases partly offsets the strong warming effect in the Fixasia 
simulations. As shown in Fig. 8a, about $27.0 \%$ of the positive trends in TXx, $28.2 \%$ of the positive trends in TNx, $25.8 \%$ of the positive trends in TXn, and $16.7 \%$ of the positive trends in TNn in response to the Fixasia simulations are compensated by the negative trends induced by the Asian AA increases, respectively. Thus, Asian AA increases improve the model-simulated trends of temperature extremes in comparison with those based on observations, and are likely to have moderated the recent trends in extreme temperatures in China.

The agreement of the magnitude of model-simulated trends in extreme indices with those in observations is not only over China as a whole, but also over individual sub-regions (Fig. 8c-h). The extremes index trends averaged over NC, SEC and SWC in response to All forcing changes are all comparable to those in observations, indicating a dominant role of historical forcing changes in the observed trends in each sub-region.

In the Fixasia case, the positive trends in TXx, TNx, TXn, TNn, SU and TR and the negative trends in ID and FD are simulated over all the three sub-regions. The same sign of these trends in the Fixasia and All forcing transient simulations suggest that historical forcing without Asian AA changes plays a primary role in the trends in temperature extremes over each sub-region. Moreover, the magnitudes of trends in temperature extremes in the Fixasia simulations are almost the same over the three sub-regions, indicating that the trends of temperature extremes in the Fixaisa experiments are chiefly driven by the increases in GHGs, which have a uniform 
distribution and therefore induce a more or less uniform warming over China (e.g.,

Zhao et al. 2016). However, the magnitude of these trends is overestimated in the

Fixasia experiments over individual sub-regions, particularly over SEC and SWC, suggesting that the moderating role of Asian AA increases is particularly strong in these regions.

The trends in hot temperature extremes are stronger over NC than those over SEC and SWC in response to All forcing changes. In the All forcing transient simulations, the magnitude of trends in TXx $(\mathrm{TNx})$ are $0.34{ }^{\circ} \mathrm{C} / 10 \mathrm{yr}\left(0.34{ }^{\circ} \mathrm{C} / 10 \mathrm{yr}\right)$ over $\mathrm{NC}$, but $0.27{ }^{\circ} \mathrm{C} / 10 \mathrm{yr}\left(0.22{ }^{\circ} \mathrm{C} / 10 \mathrm{yr}\right)$ over SEC and $0.23{ }^{\circ} \mathrm{C} / 10 \mathrm{yr}\left(0.30{ }^{\circ} \mathrm{C} / 10 \mathrm{yr}\right)$ over SEC. This north-south gradient cannot be explained without Asian AA increases. The trends in temperature extremes in the Fixasia simulations are almost homogenous over the three sub-regions, while the magnitudes of changes in these hot extremes in response to Asian AA forcing are stronger over SEC and SWC, but weaker over NC [the magnitude of trends in TXx $(\mathrm{TNx})$ are $-0.16^{\circ} \mathrm{C} / 10 \mathrm{yr}\left(-0.14^{\circ} \mathrm{C} / 10 \mathrm{yr}\right)$ over SEC and $-0.24{ }^{\circ} \mathrm{C} / 10 \mathrm{yr}\left(-0.13{ }^{\circ} \mathrm{C} / 10 \mathrm{yr}\right)$ over SEC, but $-002{ }^{\circ} \mathrm{C} / 10 \mathrm{yr}\left(-0.08^{\circ} \mathrm{C} / 10 \mathrm{yr}\right)$ over NC]. The heterogeneous impacts of Asian AA on extremes on regional scale account for the north-south gradient in TXx and TNx over China.

In summary, the changes in temperature extremes in the All forcing simulations indicate that historical forcing changes play a dominant role in generating observed trends in temperature extremes. The inclusion of Asian AA increases is necessary for the reliable reproduction of the magnitude of these trends. Furthermore, the cooling 
trends induced by Asian AA increases are stronger over southern China than those over the north. This heterogeneous impact of Asian AA increases on regional scale account for the observed north-south gradient in some temperature extremes over China. These results suggest an important role for Asian AA increases in the trends in temperature extremes over China during the past four decades. In the following section, we identify the physical processes involved in the model simulated responses of temperature extremes to the historical forcing changes and to the Asian AA increases specifically.

\section{Physical processes responsible for the trends in temperature extremes}

\subsection{Physical processes in response to historical forcings}

The spatial patterns of summer (June, July and August) mean trends for the key components of surface energy balance and related variables in the All forcing transient simulations are illustrated in Fig. 9. The SAT exhibits trends of $0.30{ }^{\circ} \mathrm{C} / 10 \mathrm{yr}$ in response to All forcing changes (Fig. 9a), corresponding to the positive trends in hot extremes over China. The surface warming trends are stronger over NC with a magnitude of $0.36{ }^{\circ} \mathrm{C} / 10 \mathrm{yr}$, but relatively weak over southern China with a value of $0.22{ }^{\circ} \mathrm{C} / 10 \mathrm{yr}$. The regional differences in trends of summer mean SAT are consistent with the north-south gradient of some hot extremes trends.

The surface warming trends are primarily due to the increases in clear sky longwave (LW) radiation of $2.49 \mathrm{~W} \mathrm{~m}^{-2} / 10 \mathrm{yr}$ over China (Fig. 9c). The positive 
changes means an increase in downward LW radiation overwhelmed increased upward LW radiation, which is mainly due to the direct impact of increase in GHG concentrations, and also induced by the increases of water vapor in the atmosphere (Fig. 9b), which occurs along with the surface warming over both land and ocean. The positive changes in clear sky LW radiation contribute to the positive surface LW radiation trends with a magnitude of $2.02 \mathrm{~W} \mathrm{~m}^{-2} / 10 \mathrm{yr}$ (Fig. 9d), although they are partly compensated by a negative LW cloud radiative effect (LW CRE) with a value of $-0.47 \mathrm{~W} \mathrm{~m}^{-2} / 10 \mathrm{yr}$ (not shown), as a consequence of the reduction in cloud cover (Fig. 9e). The decrease in cloud cover over land is related to the decrease in relative humidity (not shown) since specific humidity over land increases less than specific humidity at saturation which increases with the continental surface temperature following the Clausius-Clapeyron relationship (e.g., Dong et al. 2009; Boé and Terray 2014). The reduction of cloud cover and decrease of relative humidity, being likely due to the surface warming, lead to positive shortwave cloud radiative effect (SW CRE; Fig. 9f) with trends of $0.32 \mathrm{~W} \mathrm{~m}^{-2} / 10 \mathrm{yr}$. This in turn has a positive feedback on surface warming. In summary, it is the positive changes in the clear sky LW radiation, as a consequence of increased GHG concentrations, as well as the increased water vapor in the atmosphere, that primarily contributes to the surface warming and increased trends in hot extremes in the All forcing transient simulations. In addition, the positive SW CRE, associated with the decrease of cloud cover, has a positive feedback with the surface warming, which also contributes to the positive trends in 
hot extremes.

Decreases in net surface shortwave (SW) radiation (Fig. 9g), with an amplitude of $-0.88 \mathrm{~W} \mathrm{~m}^{-2} / 10 \mathrm{yr}$, are due to the negative changes in clear sky $\mathrm{SW}$ radiation of -1.59 $\mathrm{W} \mathrm{m} \mathrm{m}^{-2} / 10 \mathrm{yr}$ over China (Fig. 9h). The decrease in net clear sky $\mathrm{SW}$ radiation is induced by the local increase of AA emissions directly through the aerosol-radiation interaction, with the most significant decrease of clear sky SW radiation located over East Asia and South Asia, where the AA emissions are dramatically increased. The negative changes in SW radiation and clear sky SW radiation tend to cool the surface, indicating a role of Asian AA in shaping the change in surface temperature and trends of hot extremes over China.

Figure 10 shows the spatial distributions of the winter (December to February) mean trends for the key components of surface energy balance and related variables in the All forcing transient simulations. In response to historical forcing changes, the most significant changes are the positive trends in SAT over China (Fig. 10a). The strong surface warming, with a magnitude of $0.31{ }^{\circ} \mathrm{C} / 10 \mathrm{yr}$ over China, results in the positive trends of TNx and TNn and the negative trends in ID and FD. The warming trends correspond to the positive changes of net LW radiation, as a result of the increased downward clear sky LW radiation (Fig. 10c and d). The positive trend in clear sky LW radiation, with a magnitude of $1.67 \mathrm{~W} \mathrm{~m}^{-2} / 10 \mathrm{yr}$, is partly due to the direct impact of increase in GHG concentrations and partly due to increases in atmospheric water vapor related to ocean warming (Fig. 10b). Thus, the positive clear 
sky LW radiation is stronger over SEC, where the water vapor is largely increased. In summary, the positive changes in net clear sky LW radiation due to the Greenhouse Effect and associated water vapor feedback contribute to the warming over China and leads to positive trends of TXn and TNn and negative trends of ID and FD in the All forcing transient simulations. On the other hand, the negative changes in net SW radiation and clear sky SW radiation (Fig. 10e and f), associated with the increased Asian AA, tends to induce surface cooling, indicating the moderating effect of Asian AA in the change in surface temperature and trends of cold extremes over China.

\subsection{Physical processes in response to Asian AA changes}

Figure 11 shows the spatial distributions of the summer mean trends for the key components of surface energy balance and related variables in response to increases in AA emissions over South Asia and East Asia (All minus Fixasia experiments). In response to Asian AA increases, the SAT decreases over large regions of China, particularly over southern China (Fig. 11a). Over NC, however, the cooling trends in SAT are much weaker. The negative trend in SAT is $-0.12^{\circ} \mathrm{C} / 10 \mathrm{yr}$ over southern China, but $-0.06^{\circ} \mathrm{C} / 10 \mathrm{yr}$ over NC. This north-south gradient of trends in SAT characterizes the heterogeneous impact of Asian AA changes, which is responsible for the regional variations of trends in summer SAT and hot extremes in the All forcing transient simulations.

The cooling effect driven by the Asian AA changes primarily comes from the negative change in net clear sky SW radiation induced by the local increase of Asian 
AA (Fig. 2a) directly through aerosol-radiation interactions (Fig. 11b). The amplitude

462

463

464

465

466

467

468

469

470

471

472

473

474

475

476

477

478

479

480

481

of negative changes in clear sky $\mathrm{SW}$ radiation over China is $-1.29 \mathrm{~W} \mathrm{~m}^{-2} / 10 \mathrm{yr}$.

However, the decrease of clear sky SW radiation is partly compensated by the positive changes of SW CRE, especially over NC with a trend of $0.83 \mathrm{~W} \mathrm{~m}^{-2} / 10 \mathrm{yr}$ (Fig. 11c).

The net SW radiation tends to reflect a balance between the clear sky SW radiation and the SW CRE. Thus, the downward surface SW radiation shows a strong negative trend over southern China $\left(-1.59 \mathrm{~W} \mathrm{~m}^{-2} / 10 \mathrm{yr}\right)$, but a weak trend over $\mathrm{NC}(-0.17 \mathrm{~W}$ $\mathrm{m}^{-2} / 10 \mathrm{yr}$; Fig. 11d), which corresponds to the strong negative trends in SAT over southern China and weak trends of SAT over NC (Fig. 11a).

The weak trends in SAT over NC in response to the increased Asian AA result from the positive SW CRE over $\mathrm{NC}$, which is due to the AA-induced atmosphere-cloud feedback. The increase of Asian AA tends to cool the land more than ocean (Fig. 11a) inducing an anomalous anticyclonic circulation over northeast Asia and a cyclonic circulation over the western North Pacific (Fig. 11e). The resultant anomalous northeasterly wind along the east coast of East Asia weakens the EASM and reduces the northward moisture transport from the ocean to East Asia. Therefore, the weakening of the EASM is associated with weaker moisture transport convergence, decreased water vapor in the atmosphere (Fig. 11g) and reduced precipitation (Fig. 11f) over large part of China. This in turn gives rise to the positive SW CRE, as a consequence of the decrease in mid-level cloud cover (Fig. 11h).

The weakened EASM in response to increased Asian AA is consistent with 
482

483

484

485

486

487

488

489

490

491

492

493

494

495

496

497

498

499

500

501 502

previous studies (e.g., Kim et al. 2016; Dong et al. 2016c; 2019; Tian et al. 2018).

These studies suggested that increases in Asian AA causes an anticyclonic circulation anomaly over the western North Pacific, which in turn leads to a reduction of precipitation over NC. Our results further suggest that the weakened EASM is associated with the aerosol-induced warming over NC. The warming signal over some regions of China due to the increased AA is also consistent with previous studies (Wen et al. 2013; Li et al. 2015; Tian et al. 2018).

In summary, the local increases in Asian AA drive a cooling effect with negative changes in clear sky SW radiation arising directly through the aerosol-radiation interaction. The cooling effect causes cooling trends in SAT and negative trends of hot extremes. Moreover, the trends in SAT in response to Asian AA increases exhibit spatial heterogeneity, with weak trends in SAT over NC, as a consequence of positive changes in SW CRE. The positive changes in SW CRE are due to the AA-induced atmosphere-cloud feedback, which could partly offset the direct cooling effect in some regions, particularly over NC. This AA-induced atmosphere-cloud feedback arises as the increase in Asian AA emissions tends to cool the land more than ocean, weakening the EASM and reducing northward moisture transport, leading to reduction of atmospheric water vapor and cloud cover, especially mid-level cloud cover over NC. This induces positive changes in SW CRE over NC, offsetting the initial cooling by Asian AA increase. The result is a weakened SAT change and weak trend in hot extremes over NC. 
direct aerosol-radiation interaction, which induces a cooling effect, and is evidenced by the negative changes in clear sky SW radiation. The other is the AA-induced atmosphere-cloud feedback, which induces warming effect, and is reflected by the positive changes in SW CRE. Competition between the two processes is particularly prevalent over NC, where the amplitude of positive changes in SW CRE is close to that of negative changes in clear sky SW radiation. Thus, the AA-induced atmosphere-cloud feedback induced warming overwhelms a large part of the cooling induced by direct aerosol-radiation interaction over NC. The changes in SW CRE tend to contribute almost half of the changes in SW radiation averaged over NC. The results are consistent with Dong et al (2019), who suggested that the aerosol-cloud interaction is the main component of the response to aerosol over larger parts of the East Asian monsoon region. aerosol-radiation interaction. The magnitude of the negative changes in clear sky SW radiation averaged over China is $-0.62 \mathrm{~W} \mathrm{~m}^{-2} / 10 \mathrm{yr}$ (Fig. 12a). During winter, the 
regions with large negative clear sky SW radiation are shifted southward slightly, compared with those in summer. This is because the AA emissions are advected southward by the mean flow during winter (Fig. 2b), while in summer the AA effects are located closer to the emission regions due to relatively weak flow. Thus, the cooling effect by the increased AA emission is significant over southern China in winter. Moreover, there is significant cooling over the Indian Ocean and western North Pacific (Fig. 12b) due to the increased AA advected by prevailing winds from South and East Asia. This cooling over the ocean results in the decrease of water vapor extending from the western North Pacific to central-eastern China (Fig. 12f), which corresponds to the decrease of cloud cover over central-eastern China (Fig. 12e). The decreases of cloud cover lead to the positive changes in SW CRE with a value of $0.31 \mathrm{~W} \mathrm{~m}^{-2} / 10 \mathrm{yr}$ over China (Fig. 12c). The net surface SW radiation with negative change in large part of China and some positive value over NC reflects the combined effect of negative changes in clear sky SW radiation and positive changes in SW CRE. Moreover, the relatively strong cooling over SWC is related to weak decrease in clear sky SW radiation and negative trends in SW CRE, which result from the increased cloud cover over SWC (Fig. 12e). The increase in cloud cover is a consequence of local surface and atmospheric cooling and weaker changes in water vapor over SWC than the surroundings (Fig. 12f).

$$
\text { In summary, the recent increase of Asian AA generally drives cooling over China }
$$
during winter with negative trends in clear sky SW radiation induced directly through 
aerosol-radiation interactions. AA emissions are likely to be advected by mean flow to the Indian Ocean and western North Pacific during winter, which also induces cooling there. This cooling reduces water vapor in the atmosphere and therefore reduces cloud cover over central-eastern China, leading to positive SW CRE and weakening the cooling trends in SAT and changes in cold extremes there. Moreover, the changes in water vapor are much weaker over SWC than the surroundings, inducing an increase in cloud cover and therefore relatively weak changes in clear sky SW radiation and large negative trends in SW CRE over SWC, consistent with the large cooling trends in SAT and changes in cold extremes there.

\section{Conclusions}

Significant trends in temperature extremes over China have been observed since the 1970s. There have been increases in the amplitude and frequency of hot extremes (positive trends in TXx, TNx, SU and TR), and decreases in the amplitude and frequency of cold extremes (positive trends in TXn and TNn and negative trends in ID and FD). In this study, we performed a set of transient experiments with a fully coupled atmosphere-ocean model, HadGEM3-GC2, to assess the contribution of historical forcing changes to the observed trends in temperature extremes, and attribute the role of the recent increase in Asian AA emissions in these trends.

The All forcing transient simulations successfully reproduce the magnitude and spatial pattern of the historical trends in temperature extremes. In particular, the observed north-south gradient in the trends of some hot extremes, with stronger 
positive trends over northern China than those over southern China, is also captured by the simulations. The good agreement between modeled and observed trends indicates a dominant role of historical forcing changes in the trends in temperature extremes over China since the 1970s.

Simulations with fixed Asian AA emissions tend to overestimate the trends in temperature extremes, implying a role for Asian AA increases in modulating the observed trends in temperature extremes. The Asian AA increases drive a cooling effect, which partly offsets the warming due to increasing GHG concentrations. The heterogeneous impacts of Asian AA increases also account for some of the observed regional variations in trends in temperature extremes over China. In summer, the spatial heterogeneity of the impacts of Asian AA changes arises as AA-induced atmosphere and land surface feedbacks cause regional warming trends, which weaken the initial cooling effect of Asian AA over northern China. As a result, the cooling trends induced by Asian AA changes are stronger over southern China than northern China, which results in the observed north-south gradient of trends in hot extremes. In winter, southward advection of emissions by the mean flow means that AA again causes larger cooling trends over southern China. This gradient is strengthened by reductions in cloud cover over central-eastern China, which weakens the cooling trends there, and an increase of cloud cover and strong cooling over southwestern China.

Our study indicates a dominant role of increased GHG concentrations in the 
observed trends of temperature extremes over China during the last four decades, with Asian AA emissions playing an important role in determining the spatial pattern of those trends. In the next few decades, the GHG concentrations will continue to rise and AA emissions over Asia will decline due to air quality measure. Our results imply that current trends in temperature extremes over China are likely to continue, or even to amplify, in the near future, suggesting an urgent need to establish strategies for adaptation and mitigation policies to limit damages caused by the hot temperature extremes.

\section{Acknowledgements}

This study was supported by the National Natural Science Foundation of China under Grants 41675078, U1502233, 41320104007, by the Youth Innovation Promotion Association of CAS (No. 2018102) and by the UK-China Research \& Innovation Partnership Fund through the Met Office Climate Science for Service Partnership (CSSP) China as part of the Newton Fund. BD is supported by the U.K. National Centre for Atmospheric Science-Climate (NCAS-Climate) at the University of Reading. 
603

604

605

606

607

608

609

610

611

612

613

614

615

616

617

618

619

620

621

622

623

\section{References}

Ainsworth, E. A., and D. R. Ort, 2010: How do we improve crop production in a warming world? Plant Physiol., 154, 526-530.

Alexander, L. V., and Coauthors, 2006: Global observed changes in daily climate extremes of temperature and precipitation. J. Geophys. Res., 111, D05109, doi: 10.1029/2005JD006290.

Bannister, D., M. Herzog, H. Graf, J. S. Hosking, and C. A. Short, 2017: An assessment of recent and future temperature change over the Sichuan basin, china, using CMIP5 climate models. J. Climate, 30, 6701-6722.

Barsugli, J., and D. S. Battisti, 1998: The basic effects of atmosphere-ocean thermal coupling on midlatitude variability. J. Atmos. Sci., 55, 477-493, doi:10.1175/1520-0469.

Bellouin, N., O. Boucher, J. Haywood, and Coauthors, 2007: Improved representation of aerosols for HadGEM2. Hadley Centre Technical Note, 73pp.

Chen, W., and B. W. Dong, 2018: Anthropogenic impacts on recent decadal change in temperature extremes over china: relative roles of greenhouse gases and anthropogenic aerosols. Climate Dyn., 6, 1-18.

Christidis, N., and Coauthors, 2013: A new HadGEM3-A-based system for attribution of weather and climate-related extreme events. J. Climate, 26, 2756-2783, doi:10.1175/JCLI-D-12-00169.1.

Cubasch, U., and Coauthors, 2001: Projections of future climate change. Climate 

University Press, 525-582.

626

627

628

629

630

631

632

633

634

635

636

637

638

639

640

641

642

643

644

Díaz, J., R. García, and C. López., 2005: Mortality impact of extreme winter temperatures. Int. J. Biometeor., 49, 179-183.

Donat, M. G., L. V. Alexander, H. Yang, I. Durre, R. Vose, and J. Caesar, 2013: Global land-based datasets for monitoring climatic extremes. Bull. Amer. Meteor. Soc., 94, 997-1006, doi:10.1175/BAMS-D-12-00109.1.

Dong, B-W., L. Wilcox, E. Highwood, and R. T. Sutton, 2019: Impacts of recent decadal changes in Asian aerosols on the East Asian summer monsoon: roles of aerosol-radiation and aerosol-cloud interactions. Climate Dyn., 49, 1-22.

-—, R. T. Sutton, L. Shaffrey, and N. P. Klingaman, 2017: Attribution of forced decadal climate change in coupled and uncoupled ocean-atmosphere model experiments. J. Climate, 30, 6203-6223.

—_ _ — , and L. Shaffrey, 2016a: Understanding the rapid summer warming and changes in temperature extremes since the mid-1990s over Western Europe. Climate Dyn., 48, 1537-1554, doi:10.1007/s00382-016-3158-8.

——, - —, W. Chen, X. D. Liu, R. Lu, and Y. Sun, 2016b: Abrupt summer warming and changes in temperature extremes over Northeast Asia since the mid-1990s: Drivers and physical processes. Adv. Atmos. Sci., 33(9), 1005-1023, doi: 10.1007/s00376-016-5247-3.

——, - —, E. Highwood, and L. Wilcox, 2016c: Preferred response of the East 

Asian summer monsoon to local and nonlocal anthropogenic sulphur dioxide emissions. Climate Dyn., 46, 1733-1751.

- - J. M. Gregory, and R. T. Sutton, 2009: Understanding land-sea warming contrast in response to increasing greenhouse gases. Part I: Transient adjustment. J. Climate, 22, 3079-3097.

Douville, H., 2005: Limitations of time-slice experiments for predicting regional climate change over south Asia. Climate Dyn., 24(4), 373-391.

Goderniaux, P., S. Brouyeère, S. Blenkinsop, A. Burton, H. J. Fowler, P. Orban, and A. Dassargues, 2011: Modeling climate change impacts on groundwater resources using transient stochastic climatic scenarios. Water Resour. Res., 47, W12516, doi:10.1029/2010WR010082.

Guan, Y., X. Zhang, F. Zheng, and B. Wang, 2015: Trends and variability of daily temperature extremes during 1960-2012 in the Yangtze River Basin. China Glob. Planet Chang, 124, 79-94.

Hansen, J., M. Sato, and R. Ruedy, 1997: Radiative forcing and climate response. $J$. Geophys. Res., 102, 6831-6864, doi:10.1029/96JD03436.

He, J., and B. Soden, 2016: Does the lack of coupling in SST-forced atmosphere-only models limit their usefulness for climate change studies? J. Climate, 29, 4317-4325, doi:10.1175/JCLI-D-14-00597.1

Hendon, H. H., E.-P. Lim, and G. Liu, 2012: The role of air-sea interaction for prediction of Australian summer monsoon rainfall. J. Climate, 25, 1278-1290, 
666

667

668

669

670

671

672

673

674

675

676

677

678

679

680

681

682

683

684

685

686

doi:10.1175/JCLI-D-11-00125.1.

Hertel, T. W., and S. D. Rosch, 2010: Climate change, agriculture, and poverty. Appl. Econ. Perspect Pol., 32, 355-385.

Hong, X., R. Lu, and S. Li, 2017: Amplified summer warming in Europe-West Asia and Northeast Asia after the mid-1990s. Env. Res. Lett., 12, 094007.

IPCC, 2013: Climate Change 2013: The Physical Science Basis. Contribution of Working Group I to the Fifth Assessment Report of the Intergovernmental Panel on Climate Change. Cambridge University Press, Cambridge, UK and New York, USA, 1535pp.

Kamae, Y., H, Shiogama, M. Watanabe, and M. Kimoto, 2014: Attributing the increase in Northern Hemisphere hot summers since the late 20th century. Geophys. Res. Lett., 41, 5192-5199, doi:10.1002/2014GL061062.

Kim, Y. H., S. K. Min, X. Zhang, F. Zwiers, L. V. Alex-ander, M. G. Donat, and Y. S. Tung, 2015: Attribution of extreme temperature changes during 1951-2010. Climate Dyn., 46, 1769-1782, doi:10.1007/ s00382-015-2674-2.

Kim, M. J., S.-W. Yeh, and R. J. Park, 2016: Effects of sulfate aerosol forcing on East Asian summer monsoon for 1985-2010, Geophys. Res. Lett., 43, 1364-1372, doi:10.1002/2015GL067124.

Kosaka, Y., and S. P. Xie, 2013: Recent global-warming hiatus tied to equatorial Pacific surface cooling. Nature, 501, 403-407.

Li, C. X., T. B. Zhao, and K. R. Ying, 2015: Effects of anthropogenic aerosols on 
temperature changes in China during the twentieth century based on CMIP5 models. Theor. Appl. Climatol., 125, 1-12, doi: 10.1007/s00704-015-1527-6.

Li, Z., and Coauthors, 2016: Comparison of two homogenized datasets of daily maximum/mean/minimum temperature in China during 1960-2013. J. Meteor. Res., 30(1), 053-066, doi: 10.1007/s13351-016-5054-x.

Ma, S. M., T. Zhou, D. Stone, O. Angelil, and H. Shiogama, 2017: Attribution of the July-August 2013 heat event in central and eastern China to anthropogenic Greenhouse gas emissions. Env. Res. Lett., 12, 054020.

Meehl, G. A., and Coauthors, 2000: An introduction to trends in extreme weather and climate events: Observations, socioeconomic impacts, terrestrial ecological impacts, and model projections. Bull. Amer. Meteor. Soc., 81, 413-416.

Penner, J. E., M. O. Andreae, H. Annegarn, L. Barrie, J. Feichter, D. Hegg, and G. Pitari, 2001: Aerosols, their direct and indirect effects. Climate Change 2001: the scientific basis. Contribution of Working Group I to the third assessment report of the intergovernmental panel on climate change. Cambridge University Press, pp 289-348.

Qi, L., and Y. Wang, 2012: Changes in the observed trends in extreme temperatures over china around 1990. J. Climate, 25(15), 5208-5222.

Schaller, N., and Coauthors, 2016: Human influence on climate in the 2014 southern England winter floods and their impacts. Nature Climate Change, 6, 627-634. doi:10.1038/nclimate2927 
Shi, J., L. Cui, Y. Ma, H. Du, and K. Wen, 2018: Trends in temperature extremes and their association with circulation patterns in china during 1961-2015. Atmos. Res., 212, 259-272.

Song, F., T. Zhou, and Y. Qian, 2014: Responses of East Asian summer monsoon to natural and anthropogenic forcings in the 17 latest CMIP5 models. Geophys. Res. Lett., 41, doi:10.1002/2013GL058705.

Steinman, B. A., M. E. Mann, and S. K. Miller, 2015: Atlantic and Pacific multidecadal oscillations and Northern Hemisphere temperatures. Science, 347, 988-991.

Stevens, B., and G. Feingold, 2009: Untangling aerosol effects on clouds and precipitation in a buffered system. Nature, 461, 607-613, doi:10.1038/nature08281.

Sun, Y., X. Zhang, F. W. Zwiers, L. Song, H. Wan, T. Hu, H. Yin, and G. Ren, 2014: Rapid increase in the risk of extreme summer heat in Eastern China. Nature Climate Change, 4, 1082-1085, doi:10.1038/ncli-mate2410.

Tian, F. X., B. W. Dong, J. Robson, and R. T. Sutton, 2018: Forced decadal changes in the East Asian summer monsoon: the roles of greenhouse gases and anthropogenic aerosols. Climate Dyn., 6, 1-17.

Trenberth, K. E., J. T. Fasullo, G. Branstator, and A. S. Phillips, 2014: Seasonal aspects of the recent pause in surface warming. Nature Climate Change, $\mathbf{4}$, 911-916. 
Wang, C., 2004: A modeling study on the climate impacts of black carbon aerosols. $J$. Geophys. Res., 109(3), 1-28.

Wang, Y., B. Zhou, D. Qin, J. Wu, R. Gao, and L. Song, 2017: Changes in mean and extreme temperature and precipitation over the arid region of northwestern China: observation and projection. Adv. Atmos. Sci., 34(3), 289-305.

Wen, H. Q., X. Zhang, Y. Xu, and B. Wang, 2013: Detecting human influence on extreme temperatures in China. Geophys. Res. Lett., 40, 1171-1176, doi:10.1002/grl.50285.

Wilcox, L. J., B. W. Dong, R. T. Sutton, E. J. Highwood, 2015: The 2014 Hot, Dry Summer in Northeast Asia [in "Explaining Extreme Events of 2014 from a Climate Perspective"]. Bull. Amer. Meteor. Soc., 96(12), S105-S110, doi:10.1175/BAMS-D-15-00123.1.

Williams, K. D., and Coauthors, 2015: The met office global coupled model 2.0 (GC2) configuration. Geoscientific Model Development, 8(5), 1509-1524.

Wood, N., A. Staniforth, A. White, and Coauthors, 2014: An inherently mass-conserving semi-implicit semi-Lagrangian discretization of the deep-atmosphere global non-hydrostatic equations. Quart. J. Roy. Meteor. Soc., 140(682), 1505-1520.

Yin, H., Y, Sun, H. Wan, X. B. Zhang, and C. H. Lu, 2016: Detection of anthropogenic influence on the intensity of extreme temperatures in China. Int. J. Climatol., 37, 1229-1237, doi: 10.1002/joc.4771. 
750

751

752

753

754

755

756

757

758

759

760

761

Yu, Z., and X. Li, 2015: Recent trends in daily temperature extremes over northeastern China (1960-2011). Quat. Int., 380, 35-48.

Zhao, T. B., C. X. Li, and Z, Y, Zuo, 2016: Contributions of anthropogenic and external natural forcings to climate changes over China based on CMIP5 model simulations. Sci. China Earth Sci., 59, 503-517, doi: 10.1007/s11430-015-5207-2.

Zhu, J., and J. Shukla, 2013: The role of air-sea coupling in seasonal prediction of Asia-Pacific summer monsoon rainfall. J. Climate, 26, 5689-5697, doi:10.1175/JCLI-D-13-00190.1.

Zhou, B. T., Y. Xu, J. Wu, S. Dong, and Y. Shi, 2016: Changes in temperature and precipitation extreme indices over China: analysis of a high-resolution grid dataset. Int. J. Climatol., 36, 1051-106. 
Trends in Annual sulfur dioxide emissions

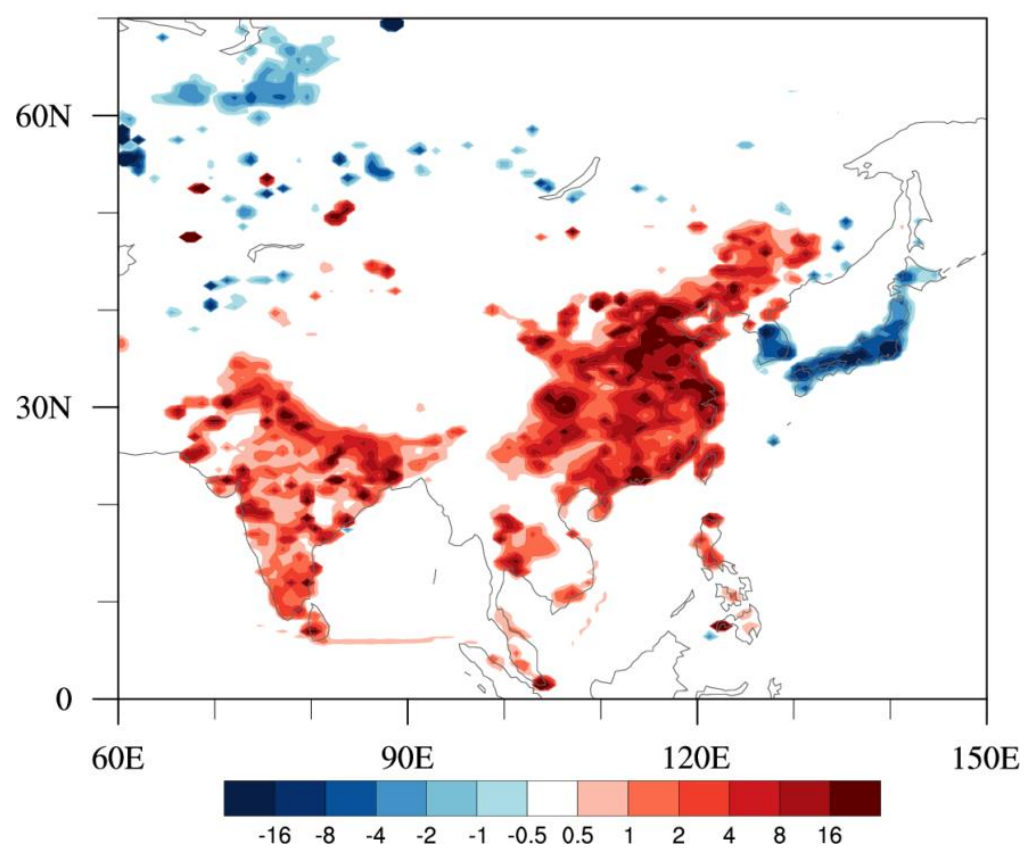

Figure 1. Spatial pattern of linear trends in annual mean sulfur dioxide emissions used in the model simulations. Units are $\mathrm{g} \mathrm{m}^{-2} \mathrm{~s}^{-1} / 10 \mathrm{yr}$. 
(a) JJA_clim_AOD (All)

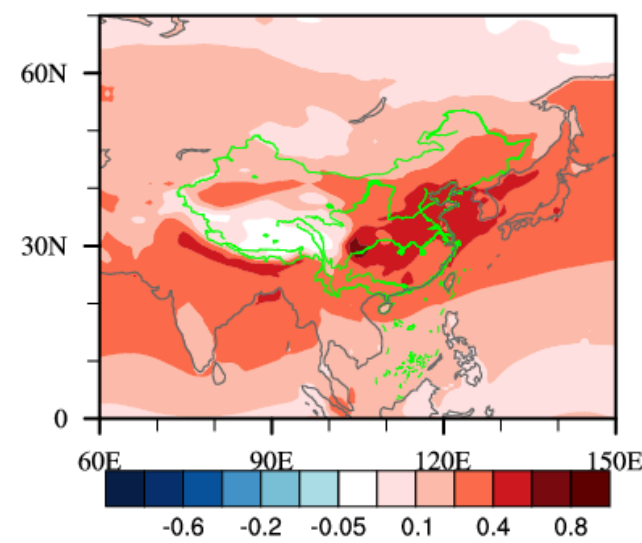

(c) JJA_clim_AOD (All-OBS)

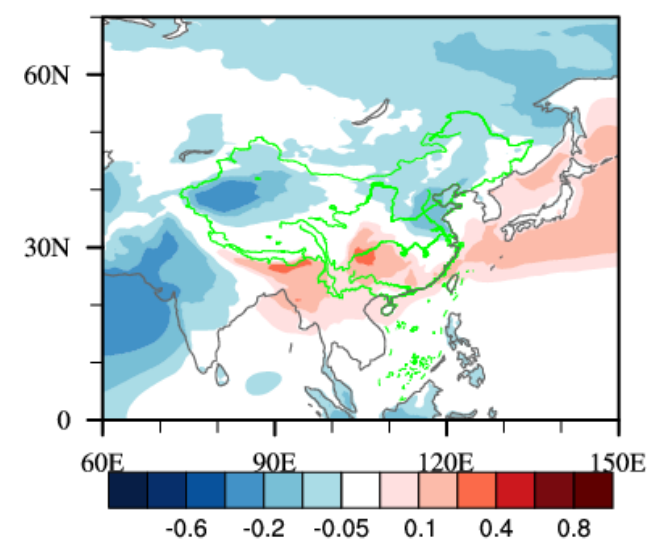

(e) JJA_clim_Tas (All-OBS)

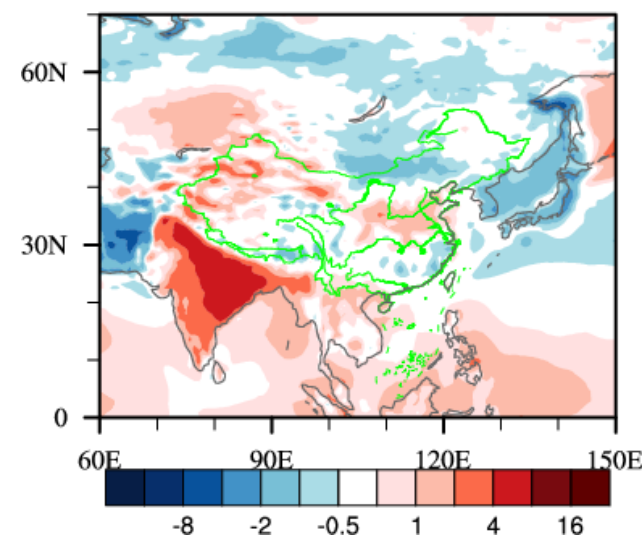

(b) DJF_clim_AOD (All)

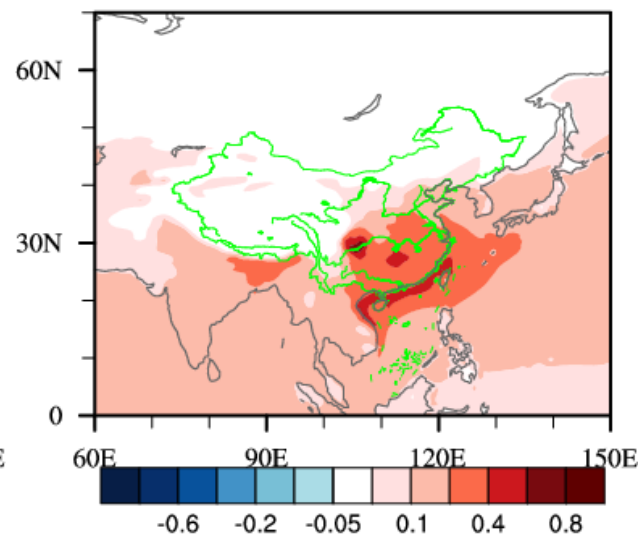

(d) DJF_clim_AOD (All-OBS)

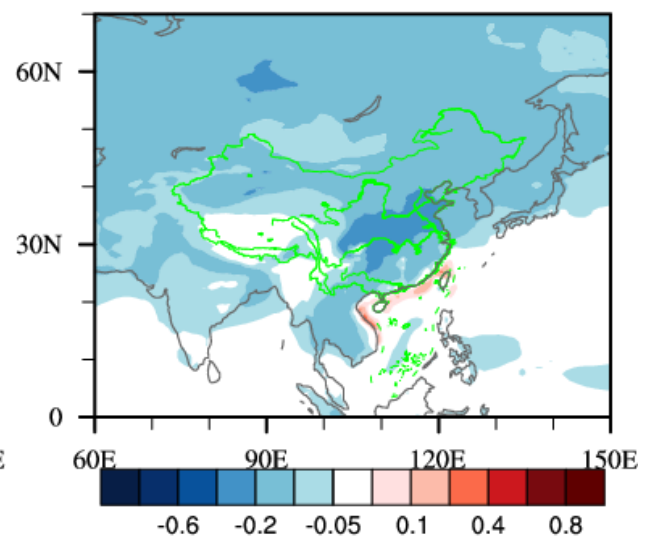

(f) DJF_clim_Tas (All-OBS)

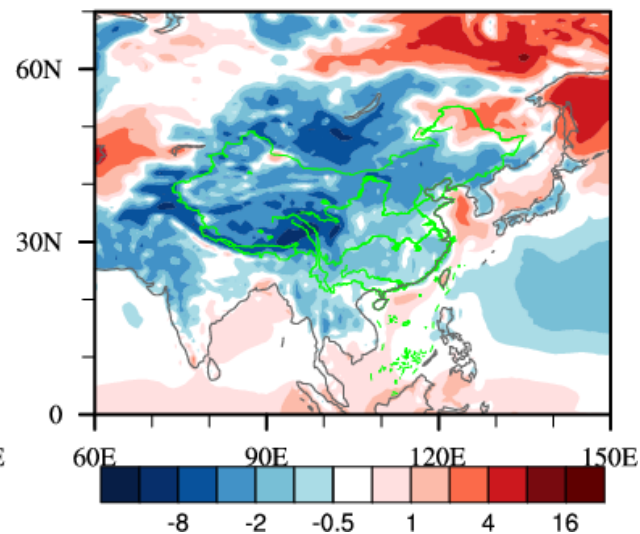

Figure 2. Climatological mean of total aerosol optical depth (AOD) at $0.55 \mu \mathrm{m}$ in the All forcing experiment $(a, b)$ and the difference with that in observations (c, d) during summer (left panels) and winter (right panels). (e, f) Differences in climatological surface air tempearutre between the All forcing experimet and observations (Units: ${ }^{\circ} \mathrm{C}$ ). The observed AOD data is from the Modern-Era Retrospective analysis for Research and Applications version 2 (MERRA-2). The observed surface air temperature data is from EAR-Interim. 

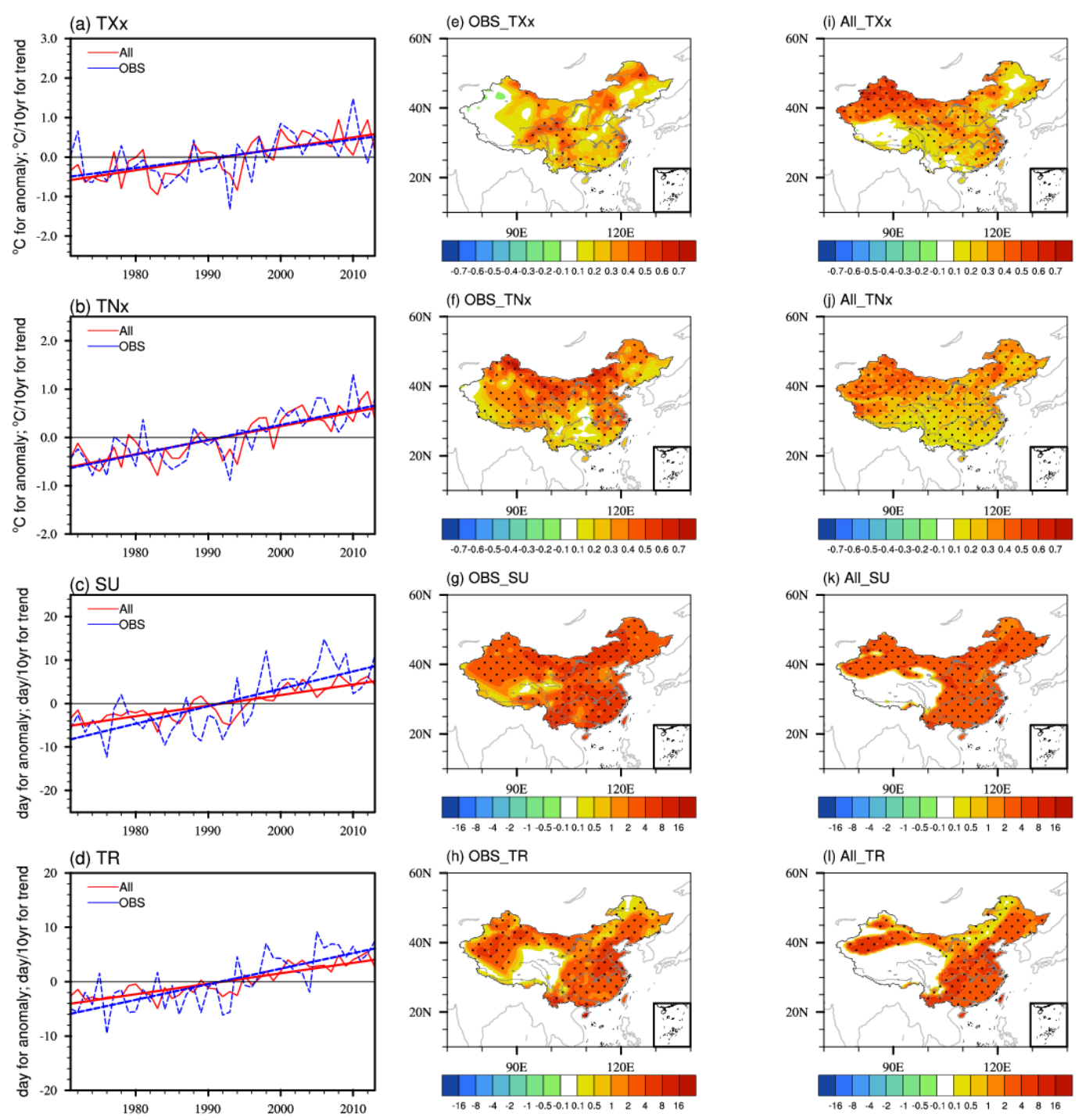

Figure 3. (a-d) Time series (dashed lines) and linear trends (solid lines) of hot temperature extreme anomalies relative to the climatology (mean of the whole period of 1971 2013) over China in observations (blue dashed lines) and in the historical transient simulations with All forcing (red solid lines; masked by China boundary). Spatial patterns of linear trend in temperature extremes from 1971 to 2013 in observations (e-h) and in the historical transient simulations with All forcing (i-l). (e)-(l) units of TXx and TNx are ${ }^{\circ} \mathrm{C} / 10 \mathrm{yr}$ and units of SU and TR are day/10yr. The regions with dots highlight the changes are statistically significant at the $90 \%$ confidence level based on a two tailed Student's t-test. 

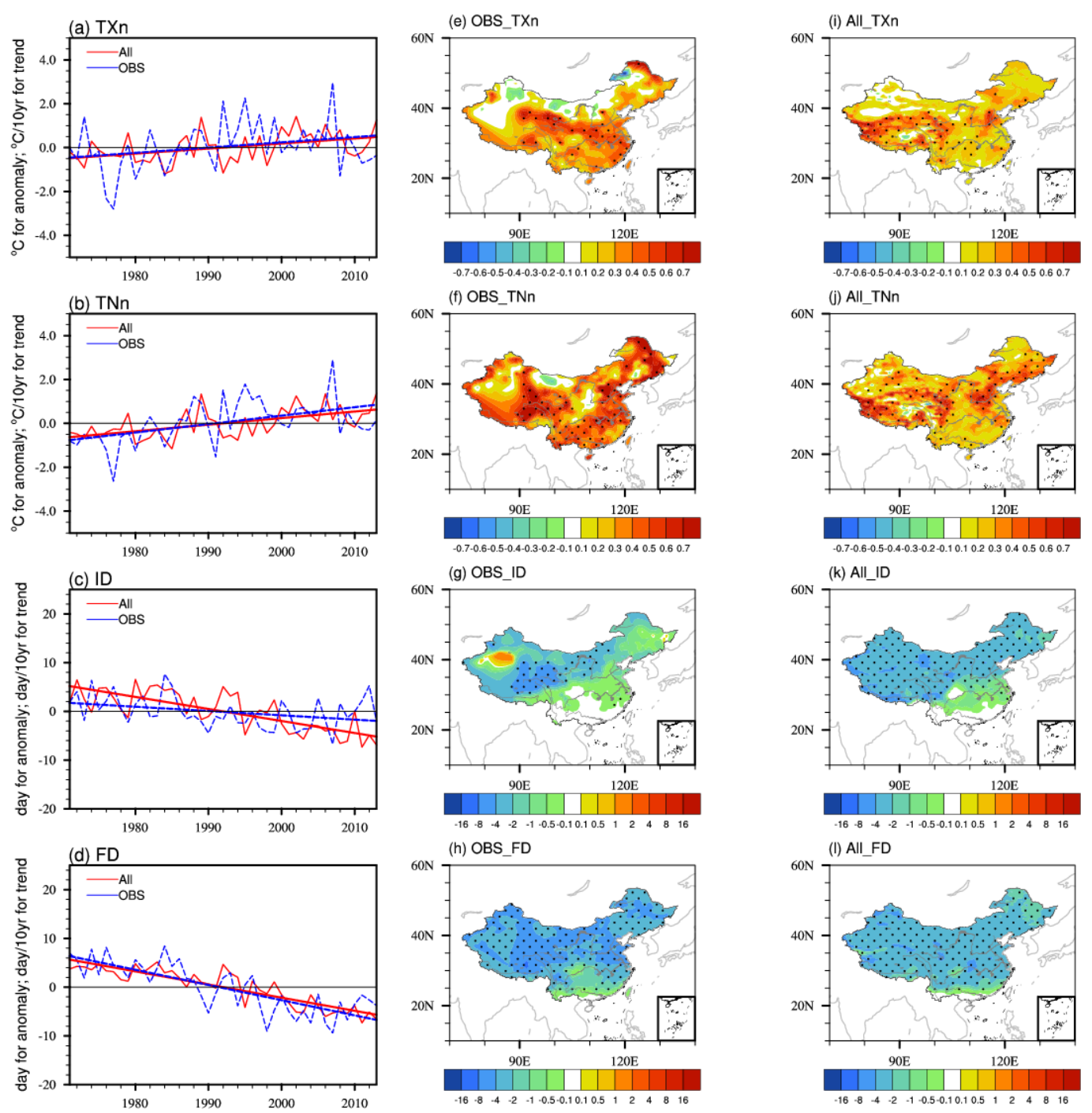

Figure 4. Same as Fig. 3, but for cold temperature extremes. (e-l) units of TXn and TNn are ${ }^{\circ} \mathrm{C} / 10 \mathrm{yr}$ and of ID and FD are day/10yr. 

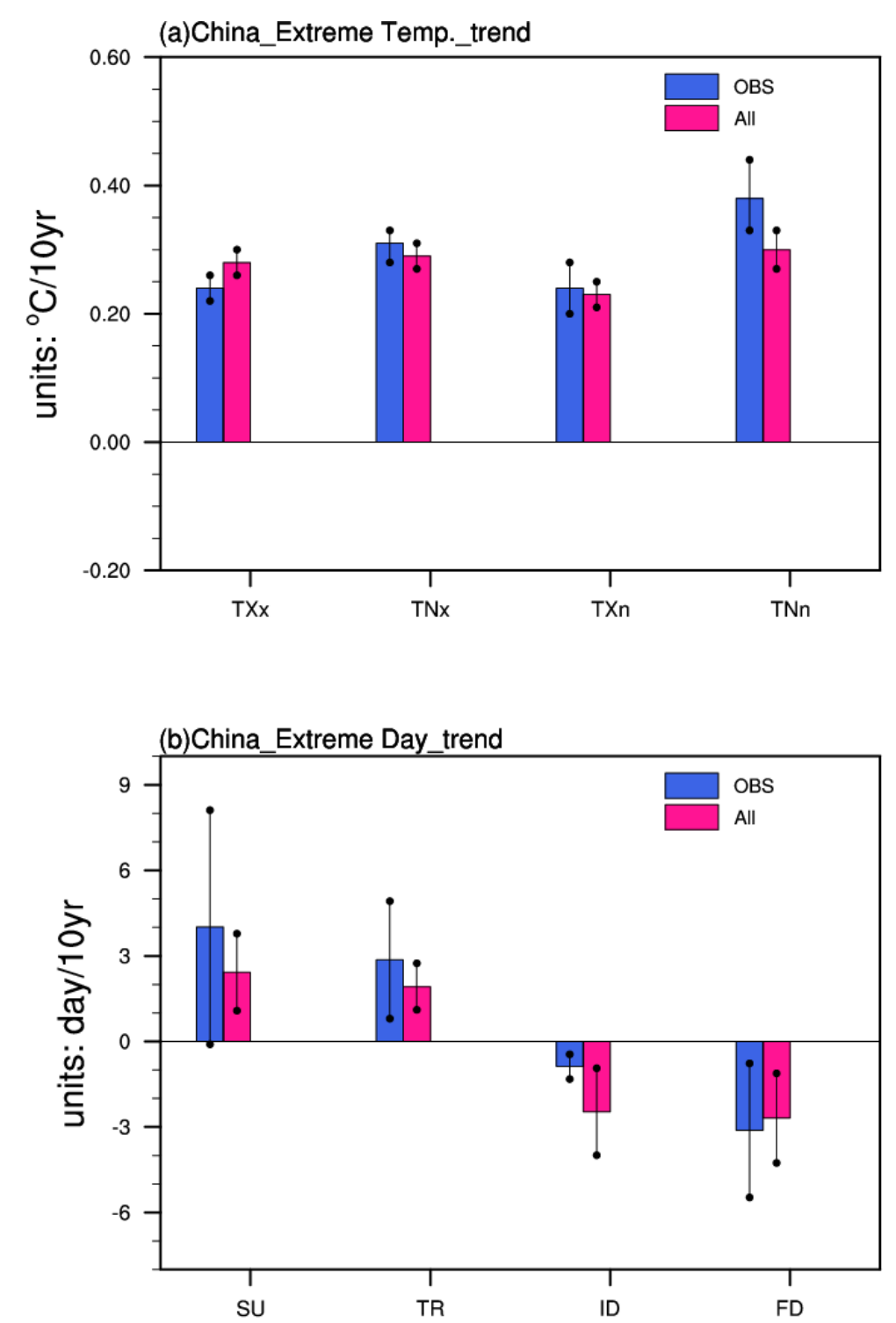

Figure 5. Observed and model simulated trends of temperature extremes in response to all forcing averaged over China. The model simulated values have been masked by the Chinese border. The color bars indicate central estimates and dots show the 95\% confidence intervals. Top panels for TXx, TXn, TNx and TNn and bottom panels for SU, TR, ID and FD. 

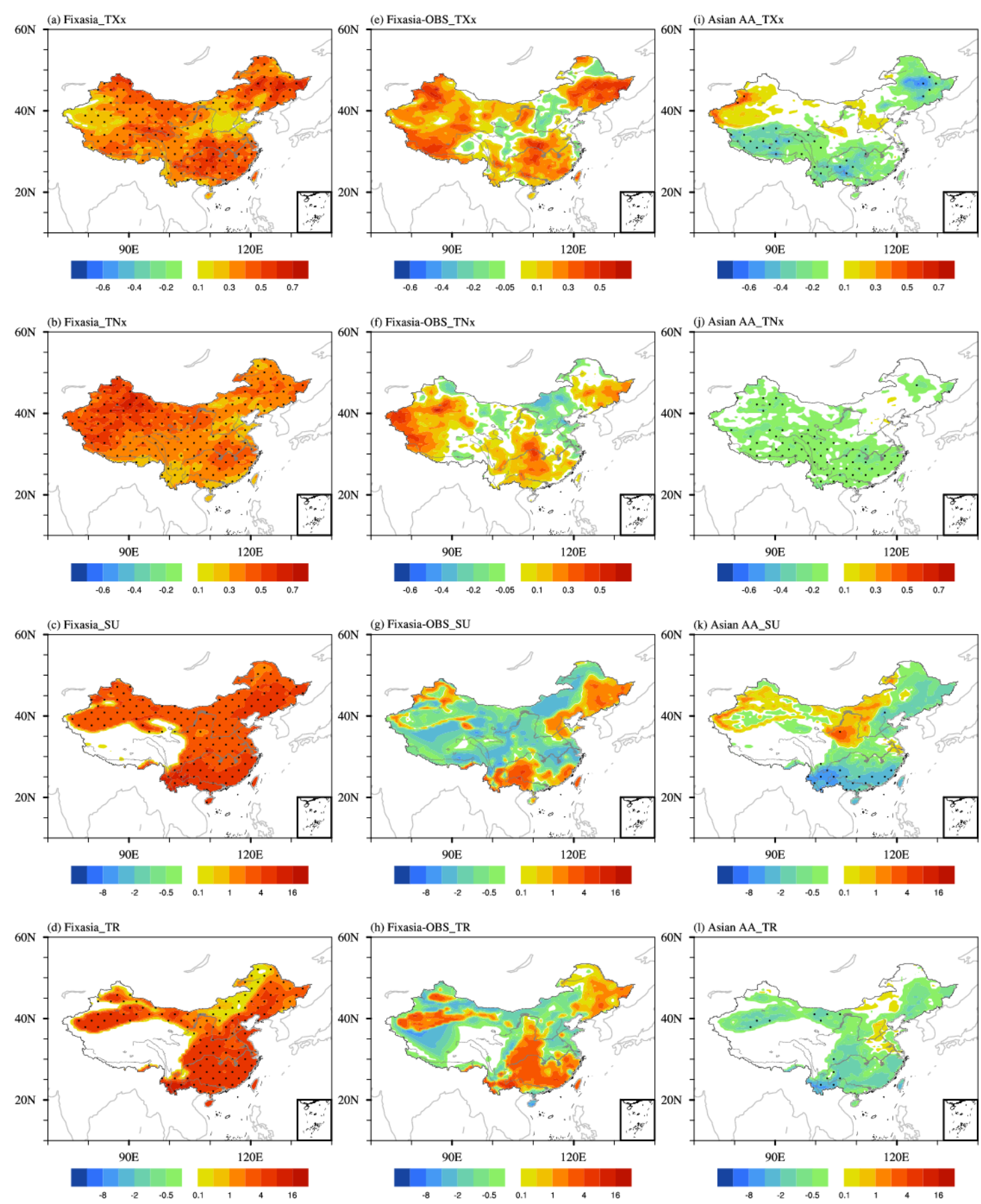

Figure 6. Spatial patterns of linear trend in hot temperature extremes in the Fixasia experiment (a-d), the differencec between the Fixasia experiment and the observations (e-h), and the All minus the Fixasia experiment (i-1). Units in TXx and TNx are ${ }^{\circ} \mathrm{C} / 10 \mathrm{yr}$. Units in SU and TR are day/10yr. The regions with dots highlight the changes are statistically significant at the $90 \%$ confidence level based on a two tailed Student's t-test. 

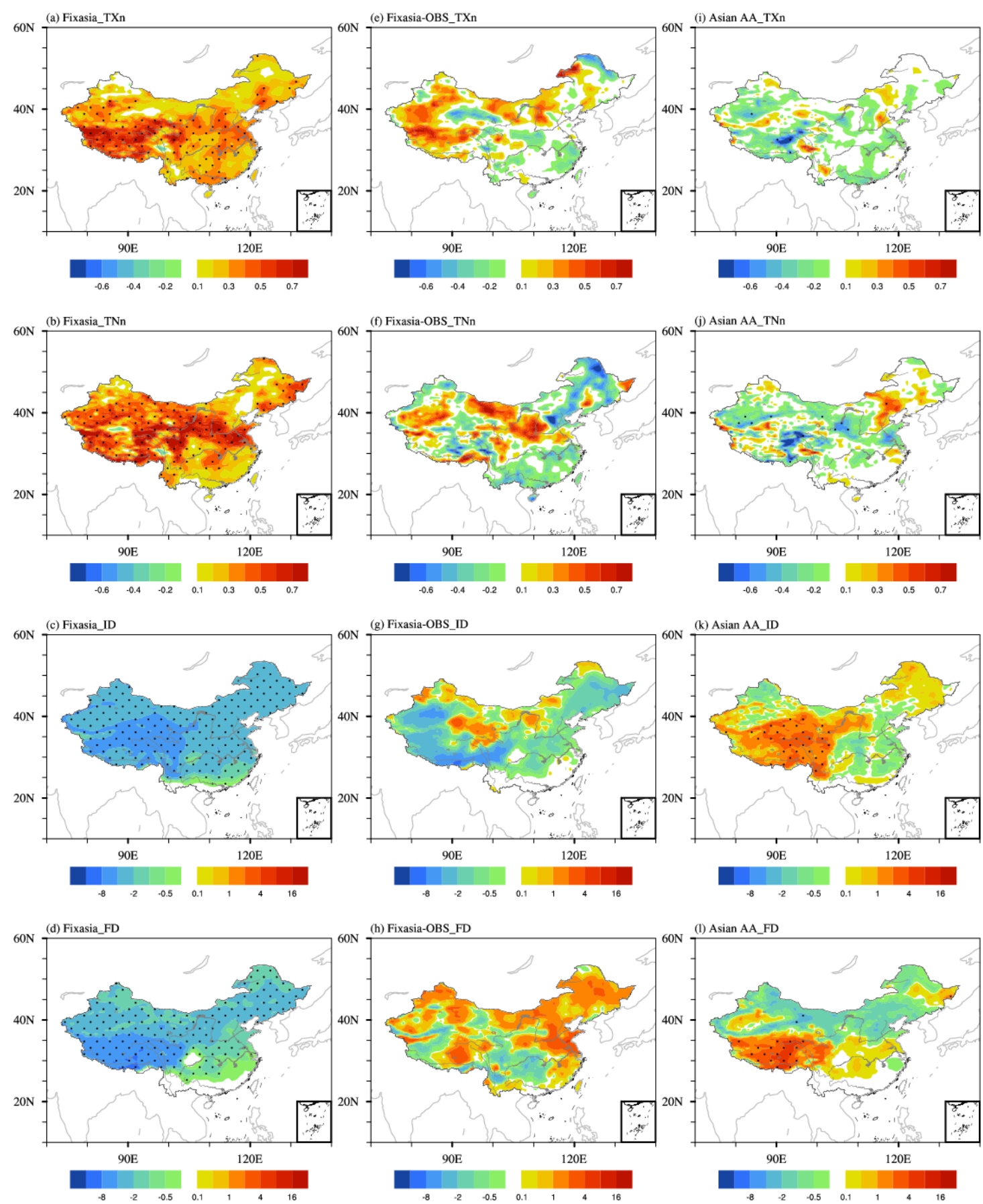

Figure 7. Same as Fig. 6, but for the cold temperature extremes. Units of TXn and TNn are ${ }^{\circ} \mathrm{C} / 10 \mathrm{yr}$ and of ID and FD are day/10yr. 

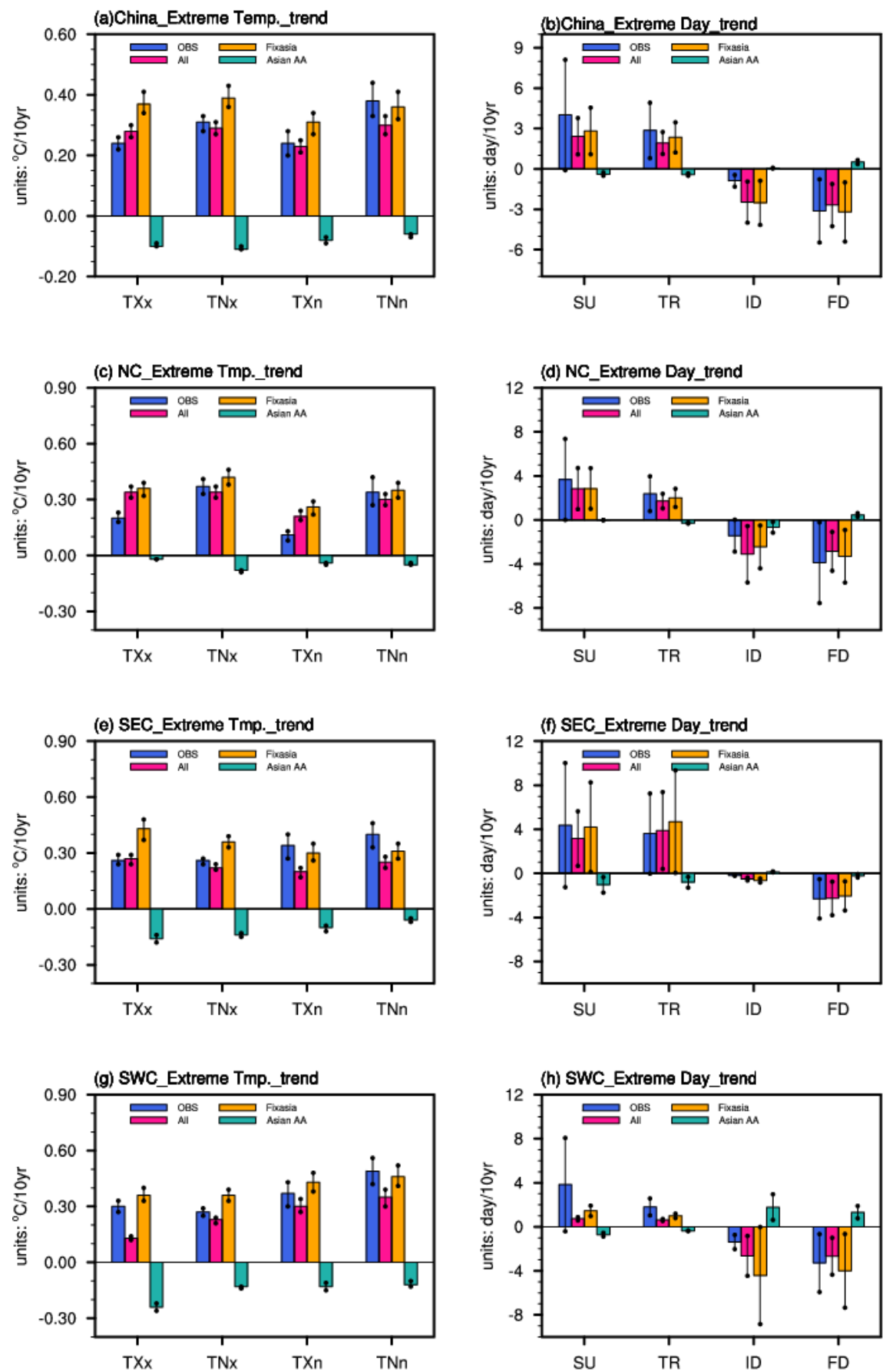

Figure 8. Observed and model simulated trends of temperature extremes in response to different forcings averaged over China as a whole $(\mathrm{a}, \mathrm{b})$ and over three subregions [northern China (c, d; NC, $35^{\circ} \sim 55^{\circ} \mathrm{N}, 75^{\circ} \sim 130^{\circ} \mathrm{E}$ ), southeastern China (e, f; SEC; $20^{\circ} \sim 35^{\circ} \mathrm{N}, 105^{\circ} \sim 130^{\circ} \mathrm{E}$ ) and southwestern China $\left.\left(\mathrm{g}, \mathrm{h} ; \mathrm{SWC} ; 20^{\circ} \sim 35^{\circ} \mathrm{N}, 75^{\circ} \sim 105^{\circ} \mathrm{E}\right)\right]$. The model simulated values have been masked by the Chinese border. The color bars indicate central estimates and dots show the $95 \%$ confidence intervals. 
(a) JJA_Tas (All)

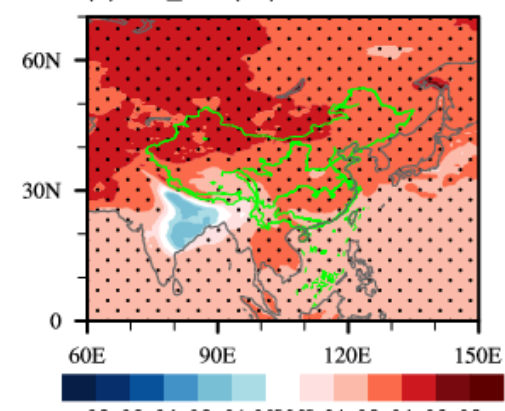

(c) JJA_clear sky LW (All)

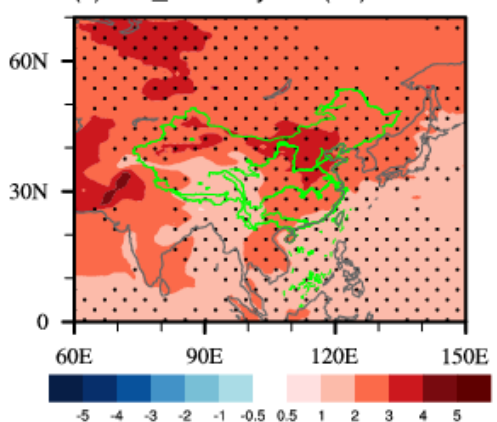

(e) JJA_Total Cloud (All)

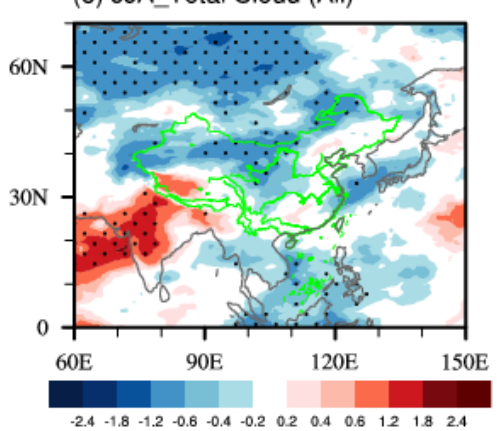

(g) JJA_SW (All)

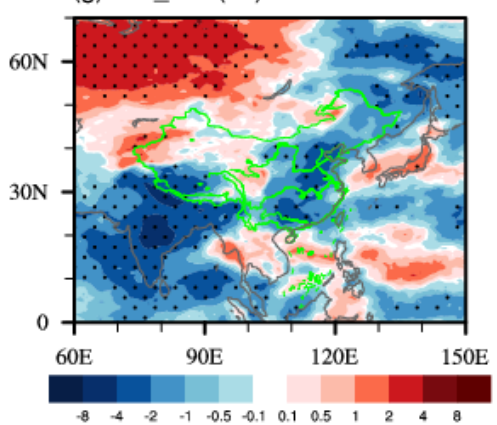

(b) JJA_Water vapor (All)

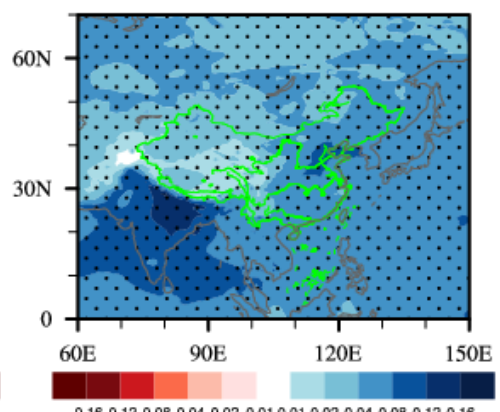

(d) JJA_LW (All)

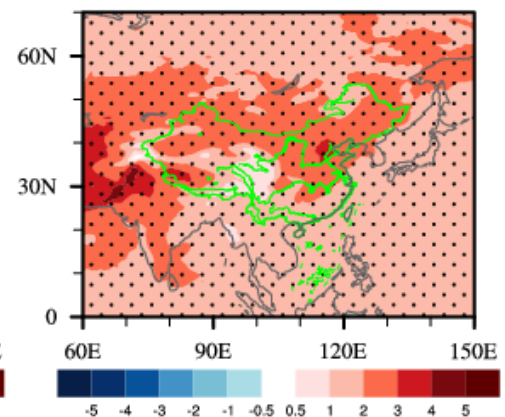

(f) JJA_SW CRE (All)

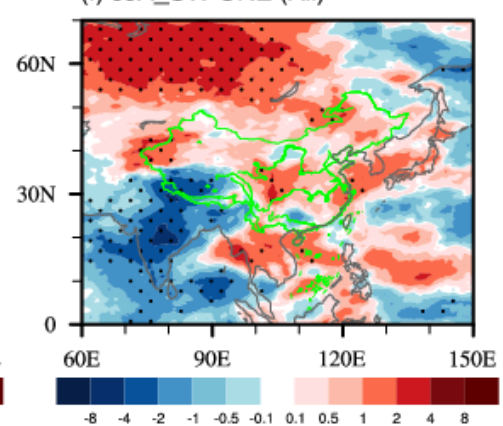

(h) JJA_clear sky SW (All)

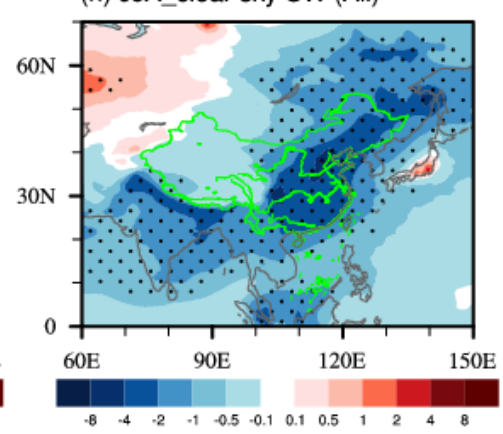

Figure 9. Spatial patterns of trends in the All forcing transient simulations during summer: (a) surface air temperature (Tas; units: ${ }^{\circ} \mathrm{C} / 10 \mathrm{yr}$ ); (b) column-integrated water vapor (units: $\mathrm{kg}$ $\mathrm{m}^{-2} / 10 \mathrm{yr}$ ); (c) clear sky LW radiation; (b) surface LW radiation; (e) total cloud cover (units: \%/10yr); (f) SW CRE; (g) surface SW radiation; and (h) clear sky SW radiation. Radiation is the net component in $\mathrm{W} \mathrm{m}^{-2} / 10 \mathrm{yr}$ and the positive value meaning downward. The regions with dots highlight the changes are statistically significant at the $90 \%$ confidence level based on a two tailed Student's t-test. 
(a) DJF_Tas (All)

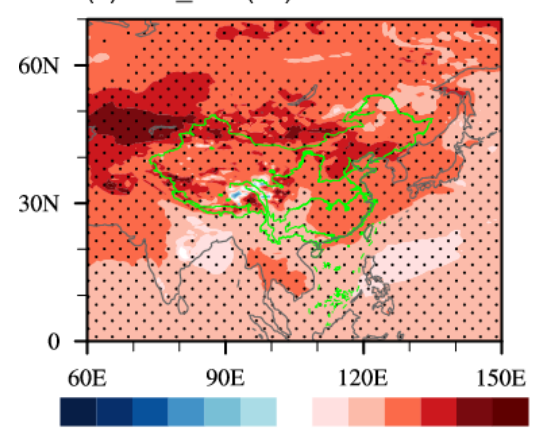

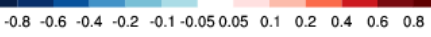

(c) DJF_LW (All)

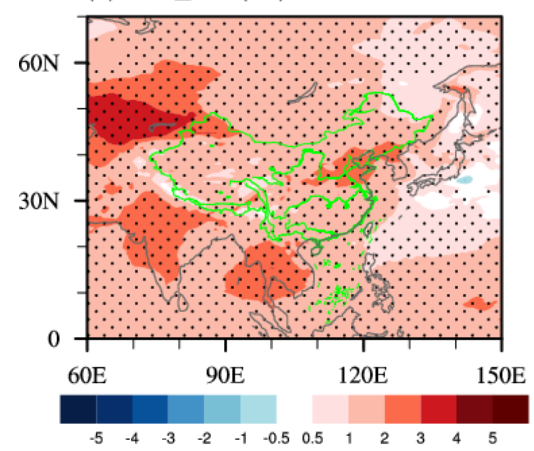

(e) DJF_SW (All)

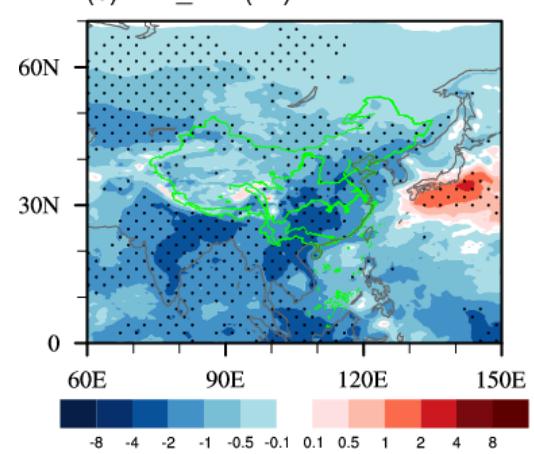

(b) DJF_Water vapor (AlI)

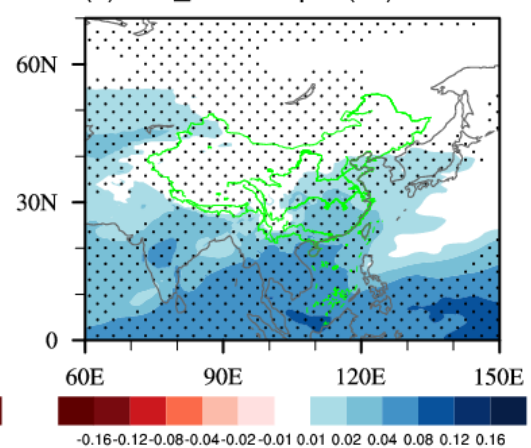

(d) DJF_clear sky LW (All)

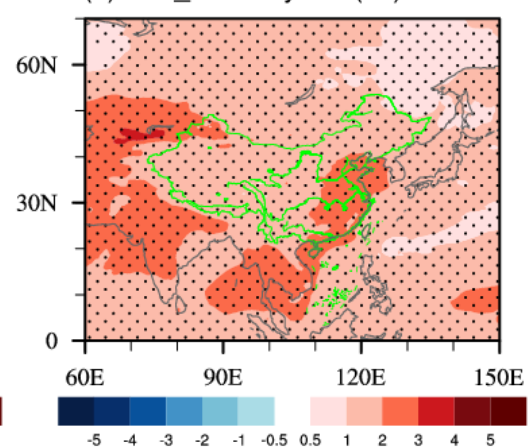

(f) DJF_clear sky SW (All)

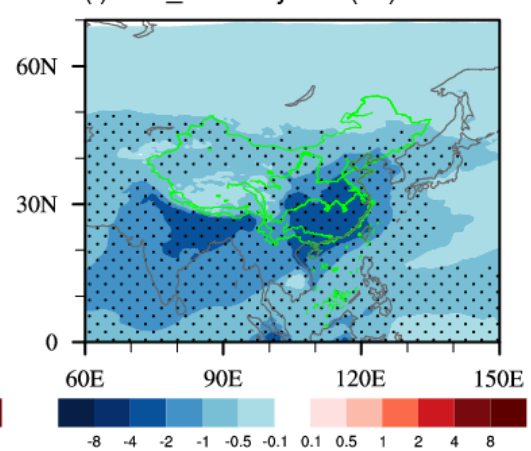

Figure 10. Spatial patterns of trends in the All forcing transient simulations during winter: (a) surface air temperature (Tas; units: ${ }^{\circ} \mathrm{C} / 10 \mathrm{yr}$ ); (b) column-integrated water vapor (units: $\mathrm{kg}$ $\mathrm{m}^{-2} / 10 \mathrm{yr}$ ); (c) surface LW radiation; (d) clear sky LW radiation; (e) SW CRE; and (f) clear sky SW radiation. Radiation is the net component in $\mathrm{W} \mathrm{m}^{-2} / 10 \mathrm{yr}$ and positive value meaning downward. The regions with dots highlight the changes are statistically significant at the $90 \%$ confidence level based on a two tailed Student's t-test. 
(a) JJA_Tas (Asian AA)

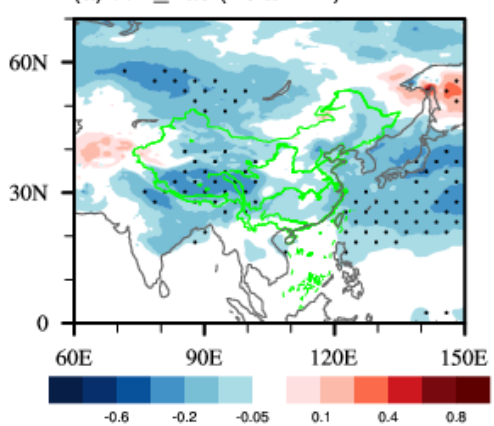

(c) JJA_SW CRE (Asian AA)

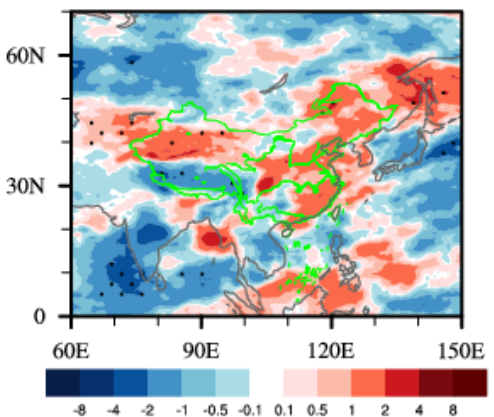

(e) JJA_700hPa Wind (Asian AA)

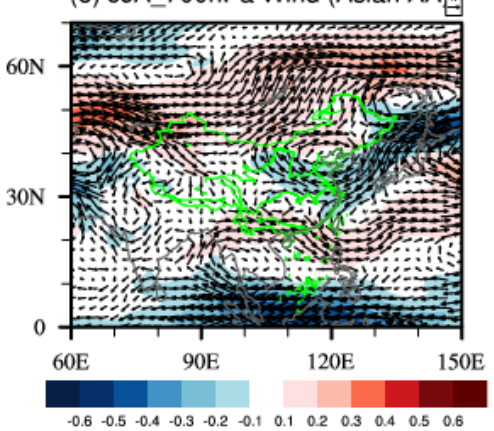

(g) JJA_Water vapor (Asian AA)

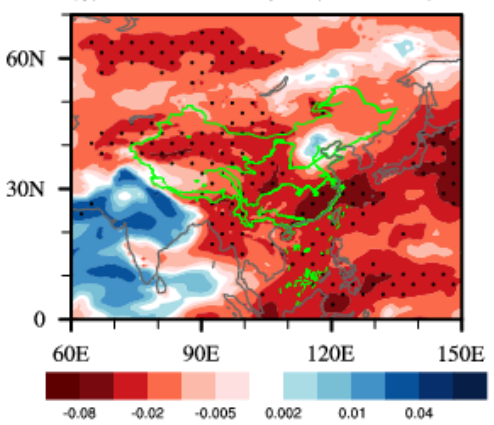

(b) JJA_clear sky SW (Asian AA)

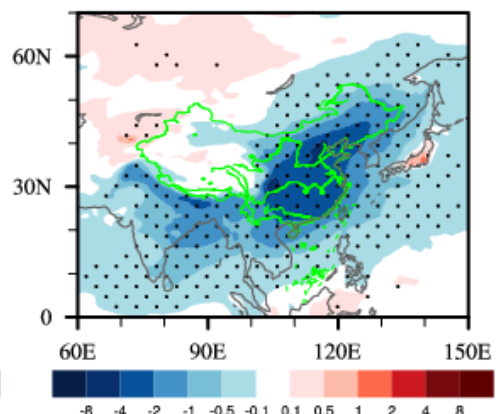

(d) JJA_SW (Asian AA)

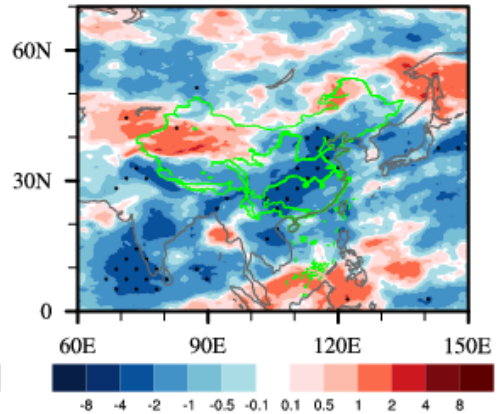

(f) JJA_Precip (Asian AA)

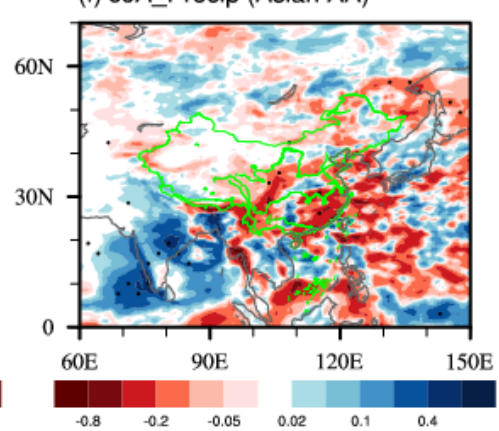

(h) JJA_Medium Cloud (Asian AA)

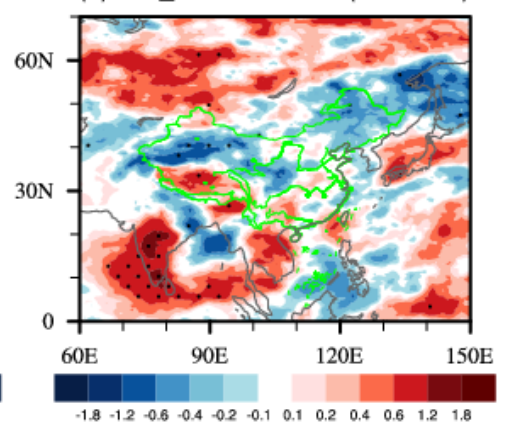

Figure 11. Spatial patterns of trends in All minus Fixasia experiments during summer: (a) surface air temperature (Tas; units: ${ }^{\circ} \mathrm{C} / 10 \mathrm{yr}$ ); (b) clear sky SW radiation; (c) SW CRE; (d) surface SW radiation; (e) 700-hPa wind (units: $\mathrm{m} \mathrm{s}^{-1} / 10 \mathrm{yr}$ ); (f) precipitation $(\mathrm{mm} / 10 \mathrm{yr}$ ); (g) column-integrated water vapor (units: $\mathrm{kg} \mathrm{m}^{-2} / 10 \mathrm{yr}$ ); and (h) Medium-level cloud cover (units: \%/10yr). Radiation is the net component in $\mathrm{W} \mathrm{m}^{-2} / 10 \mathrm{yr}$ and positive value meaning downward. The regions with dots highlight the changes are statistically significant at the $90 \%$ confidence level based on a two tailed Student's t-test. 
(a) DJF_Tas (Asian AA)

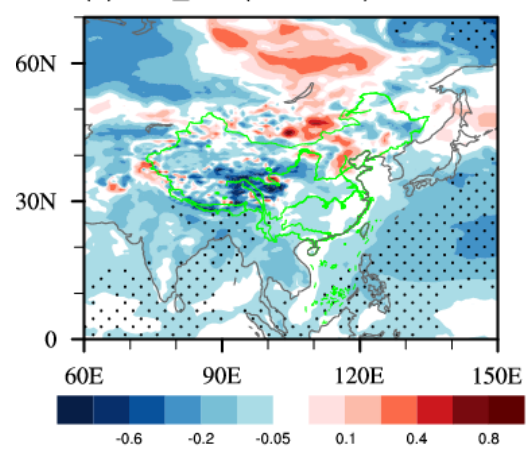

(c) DJF_SW CRE (Asian AA)

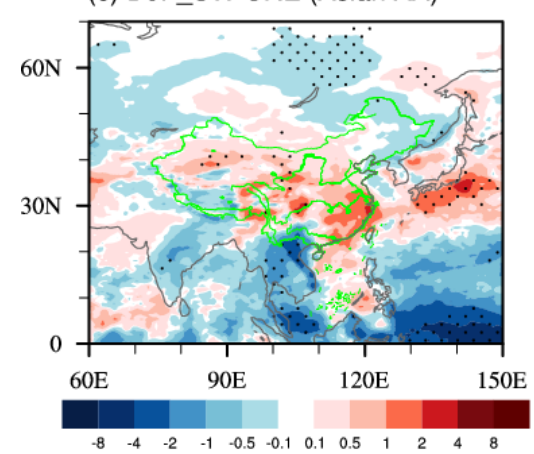

(e) DJF Total Cloud (Asian AA)

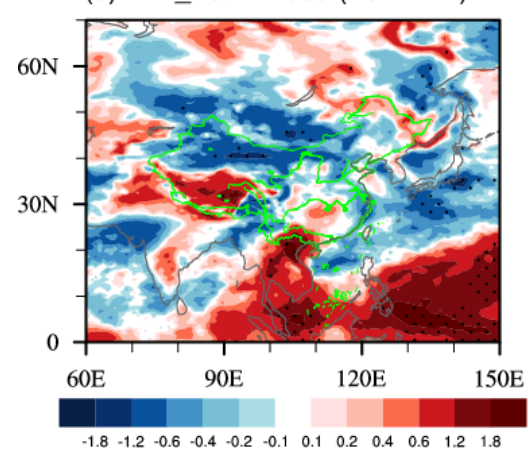

(b) DJF clear sky SW (Asian AA)

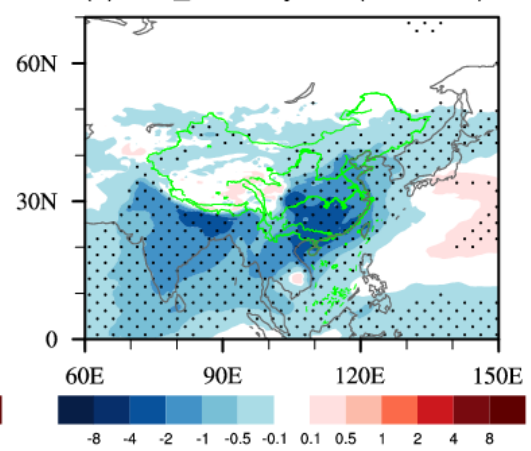

(d) DJF_SW (Asian AA)

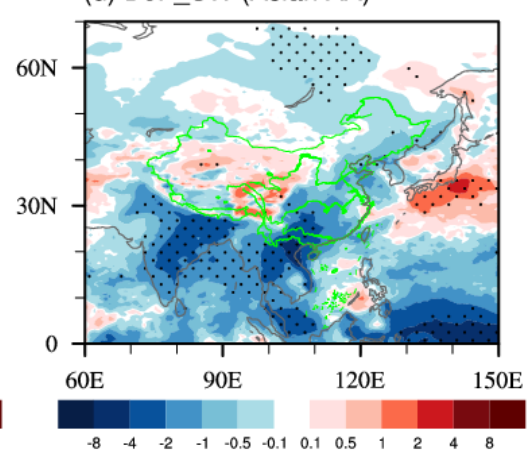

(f) DJF_Water vapor (Asian AA)

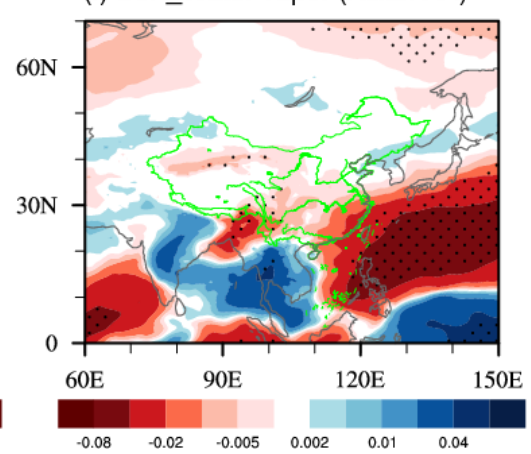

Figure 12. Spatial patterns of trends in All minus Fixasia experiments during winter: (a) surface air temperature (Tas; units: ${ }^{\circ} \mathrm{C} / 10 \mathrm{yr}$ ); (b) clear sky SW radiation; (c) SW CRE; (d) surface SW radiation; (e) total cloud cover (units: \%/10yr); and (g) column-integrated water vapor (units: $\mathrm{kg} \mathrm{m}^{-2} / 10 \mathrm{yr}$ ). Radiation is the net component in $\mathrm{W} \mathrm{m}^{-2} / 10 \mathrm{yr}$ and positive value meaning downward. The regions with dots highlight the changes are statistically significant at the $90 \%$ confidence level based on a two tailed Student's t-test. 